\title{
Evaluation of Methods to Measure Surface Level in Waste Storage Tanks
}

\author{
T. J. Peters \\ W. R. Park \\ F. M. Cuta \\ Task Manager: J. W. Voyles \\ Project Manager: J. B. Colson
}

June 1993

Prepared for Westinghouse Hanford Company and the U.S. Department of Energy under Contract DE-AC06-76RL.O 1830

Pacific Northwest Laboratory Operated for the U.S. Department of Energy by Battelle Memorial Institute

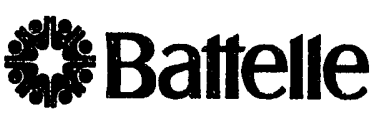




\title{
DISCLAIMER
}

This report was prepared as an account of work sponsored by an agency of the United States Government. Neither the United States Government nor any agency thereof, nor Battelle Memorial Institute, nor any of their employees, makes any warranty, expressed or implied, or assumes any legal liability or responsibility for the accuracy, completeness, or usefulness of any information, apparatus, product, or process disclosed, or represents that its use would not infringe privately owned rights. Reference herein to any specific commercial product, process, or service by trade name, trademark, manufacturer, or otherwise does not necessarily constitute or imply its endorsement, recommendation, or favoring by the United States Government or any agency thereof, or Battelle Memorial Institute. The views and opinions of authors expressed herein do not necessarily state or reflect those of the United States Government or any agency thereof.

\author{
PACIFIC NORTHWEST LABORATORY \\ operated by \\ BATTELLE MEMORIAL INSTITUTE \\ for the \\ UNITED STATES DEPARTMENT OF ENERGY \\ under Contract DE-AC06-76RLO 1830
}

Printed in the United States of America

Available to DOE and DOE contractors from the

Office of Scientific and Technical Information, P.O. Box 62, Oak Ridge, TN 37831; prices available from (615) 576-8401. FTS 626-8401.

Available to the public from the National Technical Information Service, U.S. Department of Commerce, 5285 Port Royal Rd., Springfield, VA 22161. 
PNL-8687

UC -606

\title{
EVALUATION OF METHODS TO MEASURE \\ SURFACE LEVEL IN WASTE STORAGE TANKS
}

\author{
T. J. Peters \\ W. R. Park \\ F. M. Cuta
}

Task Manager: J. W. Voyles

Project Manager: J. B. Colson

June 1993

Prepared for

Westinghouse Hanford Company and

U.S. Department of Energy

under Contract DE-ACO6-76RLO 1830

Pacific Northwest Laboratory

Richland, Washington 99352

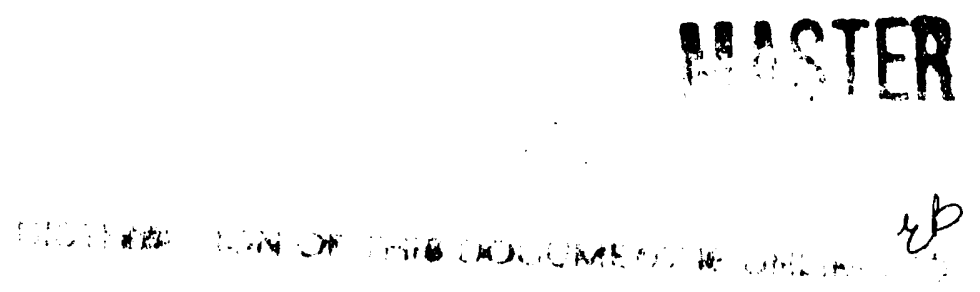




\section{SUMMARY}

This report describes the results of a program conducted at the Pacific Northwest Laboratory (PNL) and Westinghouse Hanford Company (WHC) to identify alternative methods to measure the surface level in the waste tanks. This program examined commercially available devices for measuring the distance to a target. Tests were performed with five devices to deternine their applicability to measure the surface level in the waste tanks. The devices were the Enraf-Nonius" 872 Radar Gauge, the Enraf-Nonius 854 Advanced Technology Gauge, the Stanley Tool Laser Measuring Device, the Robertshaw Inven-Te1 Precision Level Gauge, and the Micro Switch 942 Acoustic Sensor. In addition, discussions were held with several manufacturer representatives regarding other potential devices.

The results of the tests with the radar gauge indicate that the distance to the surface as measured by the radar gauge is affected by the properties of the surface even when a quarter wave notch, as suggested by the manufacturer, was placed at the end of the riser. This type of gauge could be used to measure the distance to a homogeneous liquid surface. The advantage of the radar gauge over the present Food Instrument Corporation (FIC) gauge is that it is a noncontact device that is certified to be intrinsically safe.

The Advanced Technology Gauge (ATG) consists of a weight (displacer) at the end of a stainless steel wire. When the displacer reaches the surface, the change in tension is sensed, and the amount of stainless steel wire that was released is detected to determine the distance to the surface. It is a contact device, like the FIC gauge, but does not depend on making electrical contact for determining the distance to the surface. Thus, it could be used on dry, level surfaces. In addition, it is certified to be explosion proof. If crystals build up on the displacer, it can be reweighed, which is part of the ATG software, and the new weight can be reprogrammed into the software to compensate for the crystal growth. Testing indicted that this can be accomplished. However, crystal growth will also result in a volume change of the displacer, which could result in erroneous level measurements. If the device were placed in a tank where crystals or waste could stick on the displacer, it may be necessary, depending on the density of the crystals 
compared to the density of the surface, to flush the displacer before reading the level. In addition, the distance to the surface measured by the gauge could be affected by temperature fluctuations in air above the waste surface. The displacer could not be left in the waste in a tank whose waste moves (burps) because horizontal movement of the displacer would be interpreted by the gauge as a level change. However, tests indicated that the displacer moved only slightly when placed in a small tank of water that was recirculating at a rate of $5 \mathrm{gal} . / \mathrm{min}$. For tanks where waste movement would cause inaccurate readings, it would be necessary to place the displacer of the ATG gauge in the waste only when a measurement is taken. Testing indicated that the ATG gauge can measure the distance to surfaces that are below other liquid surfaces, e.g., the levels of increasingly dense liquids, providing the volume of the displacer, or the density change between the two fluids, is large enough.

The Stanley Tool Laser Measuring Device uses a laser rangefinder technique to determine the distance to a surface. The advantage of this device is that it is a noncontact method for measuring the surface level. The prototype which was tested did not have enough power to accurately measure the distance to a waste surface. A more powerful device is to be marketed soon. It is not intrinsically safe, so probably could not be used on a hydrogen watch list tank. Discussions were held about placing the device outside the tank environment and projecting the laser beam through a window, bat the window must be designed so that water vapor does not condense on it. There is also a problem of projecting the laser beam, which travels in a straight line, through a riser that may not be straight. There are other electro-optical rangefinders on the market, but their accuracy is generally in the range of 0.2 to $0.4 \mathrm{in}$. depending on the target surface.

The Robertshaw Inven-Te10 Precision Level Gauge is a contact gauge similar to the FIC gauge presently used in the waste tank to determine surface level. Unlike the FIC gauge, the detection of slack in the tape that connects the probe to the instrument could not be used to determine the level of a nonconducting liquid. Testing indicated that the Robertshaw gauge was extremely accurate and precise as long as the resistance through the waste tank contents was below $300 \mathrm{M} \Omega$. When the resistance of the waste contents 
reached $400 \mathrm{M}$, the Robertshaw gauge could not detect the level of the waste material. Discussions with WHC indicate that the FIC probe was similarly tested and that the maximum resistance the FIC probe could have in order to detect the level of a surface was $250 \mathrm{k} \Omega$.

The MICRO SWITCH acoustic sensor was tested in a previous program but never using a simulated waste material. Testing with simulated waste was performed in this program and indicated that the device has the desired accuracy. The advantage of this device is that it is a noncontact method to measure surface level (it operates similar to radar but at a inuch lower frequency). The disadvantage of the commercial systems is that the output is not very powerful, so the acoustic sensor needs to be placed a few feet from the surface to be measured. However, commercially available acoustic sensors are not intrinsically safe or radiation hardened. A modified acoustic sensor would have to be developed for waste tank applications.

In addition to the testing, discussions were held with Omega Environmental, Inc., regarding their proprietary bubbler technique. Present accuracy is $0.1 \mathrm{in}$. in liquid storage tanks, but they claimed they could obtain higher accuracy if needed. A bubbler would have to be used in a waste tank with a clear liquid. Moore Instruments produces a system that operates on the bubbler technique, but air is not released into the fluid being tested, eliminating clogging problems. It has an accuracy of up to $\pm 0.25 \mathrm{in}$. and is made from 316 stainless steel, which should survive the caustic environment.

Discussions were also held with Krohne America, Inc., regarding their radar gauge. It is also intrinsically safe and is small enough to be placed directly into the tank rather than at the top of the riser. As with the Enraf radar gauge which was tested in this program, the distance measured by the gauge probably would still be dependent on surface parameters. However, the Krohne radar gauge can be easily configured to meet the tank requirements. For example, one of its set-up parameters may allow it to ignore a salt cake that floats in the field of view of the radar unit.

A brief survey of commercially available pressure transducers was conducted in this project. The results indicate there are several manufacturers of pressure transducers that could be used to determine level 
for waste tank applications. However, the accuracy of the device is not as high as some of the other techniques.

Based on discussions and tests conducted in this program, it appears there is no one method that can be used to measure the surface level in all of the tanks. Radar gauges will work in waste tanks that have a liquid surface, and they are intrinsically safe. The ATG gauge will work in tanks with liquid or with flat solid crusts, and it is explosion proof. It may work in other tanks providing precautions are taken to minimize crystal build up on the displacer, horizontal movement of the displacer due to surface motion, etc. Acoustic sensors are a possible noncontact method, but development work is required in order to make them radiation hardened and intrinsically safe. Laser rangefinders are also possible but need a higher power light source and a straight riser. The Robertshaw contact gauge is similar to the present FIC gauge. It may be able to detect the level of a surface that has a lower electrical conductivity.

No coating was found in the tests conducted in this program that minimized crystal growth. Testing indicated that crystals form on the FIC gauge when it is removed from the contents and left drying in the air above the waste. Leaving the probe in the waste should minimize the crystal buildup.

All of these devices only measure the distance to the surface at one or two places. Because the waste material is very inhomogeneous, it probably would be better to develop a device that will map the surface. By doing this, the level measurement could be corrected when a solid area floated underneath the measurement device. Even better would be a device which examines changes occurring below the surface, because surface changes may not reflect what is happening below the surface. A device that can detect changes inside the waste at various locations might be a more useful tool. Because of the high degree of attenuation in the waste material, this would not be a simple device to develop. The development of this concept was beyond the scope of this project and needs to be examined further. 


\section{CONTENTS}

SUMMARY

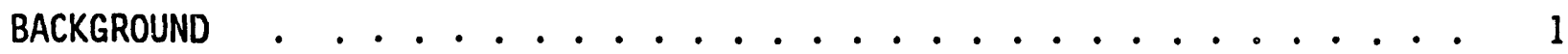

TEST RESULTS ............................. 3

ENRAF-NONIUS'M 872 RADAR GAUGE .............. 3

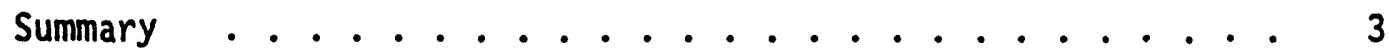

Notch Orientation ............... 3

Change in Material Properties . . . . . . . . . 6

Change in Riser Diameter ............ 8

Beam Profiles ................ 8

Reflection Diagrams ............. 12

ENRAF-NONIUSM 854 ADVANCED TECHNOLOGY GAUGE . . . . . . . 15

Summary ..................... 15

Test Set-up .................... 16

Repeatability .............. 17

Weight Compensation ............ 17

Volume Compensation ............... 19

Coating Test ................. 20

Surface Motion ............... 22

Temperature ................. 22

Solid Surface .................. 23

Stainless Steel Displacer ............. 23

STANLEY TOOL LASER MEASURING DEVICE . . . . . . . . . . 24

Summary ....................... 24

Precision of the Stanley Tool Laser Measuring Device . . . . 26

Precision of the Device Using a Folding Mirror . . . . . . 27 


\section{CONTENTS (cont inued)}

Smooth Target Versus Rough Target . . . . . . . . . . 27

Accuracy of the Device ............... 27

Effect of Device Warm-Up ... . . . . . . . . . 28

Other Targets ................... 29

Effect of Room Lights ................ 29

ROBERTSHAW 185A INVEN-TELه PRECISION LEVEL GAUGE . . . . . . . 29

Summary ..................... 29

Test Set-Up ................. 30

Repeatability ................. 30

Accuracy ................... 30

Slack Switch ................ . . 30

Resistance .................. 31

MICRO SWITCH 942 ACOUSTIC SENSOR ............... 32

Summary ..................... 32

Test Results . . . . . . . . . . . . . . 32

OTHER TECHNIQUES . . . . . . . . . . . . . . . . . . . 35

ELECTRO-OPTICAL RANGEFINDER . . . . . . . . . . . . . 35

BUBBLER ......................... 35

OTHER RADAR GAUGES .................... 36

PRESSURE TRANSDUCERS ......................... 37

CONCLUSIONS . . . . . . . . . . . . . . . . . . . . 39

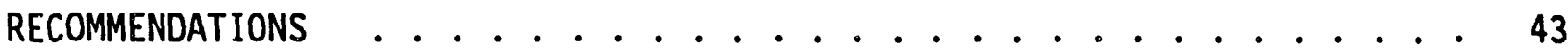

REFERENCES ........................... 45

APPENDIX A: CHEMICAL COMPONENTS IN WASTE TANK SIMULANT . . . . . . . . . A.l

APPENDIX B: LIST OF COMMERCIALLY AVAILABLE PRESSURE TRANSDUCERS $\quad$ • . . . 


\section{FIGURES}

1 Experimental Test Set-Up of Radar Gauge ............ 4

2 Reflection Diagram - Edge of 0.295 in. Notch Parallel to Electric Component .................. 4

3 Reflection Diagram - Edge of 0.295 in. Notch Perpendicular to Electric Component

4 Reflection Diagram - Edge of 0.438 in. Notch Parallel to Electric Component ................................

5 Reflection Diagram - Edge of 0.438 in. Notch Perpendicular to Electric Component .................... 7

6 Beam Topography 1 Foot from Antenna ............ 9

7 Beam Profile 1 Foot from Antenna ............. g

8 Beam Topography 1 Foot from 8 In. Pipe ........... 10

9 Beam Profile 1 foot from 8 In. Pipe ............ 10

10 Beam Topography 1 Foot from 12 In. Pipe ........... 11

11 Beam Profile 1 Foot from 12 In. Pipe ............ 11

12 Expected Reflection Diagram .............. 13

13 Reflection Diagram with Large Signal at 4.75 Meters . . . . . 13

14 Reflection Diagram with Signals Other Than Target . . . . . . . 14

15 Reflection Diagram with No Signal Until Reach Wall of the Room . 14

16 Experimental Test Set-Up of ATG .............. 17

17 Photographs of Results of Coating Test ............. 21

18 Experimental Test Set-Up of Laser Measuring Device . . . . . . 25

19 Experimental Test Set-Up for Robertshaw Gauge .......... 31 


\section{TABLES}

1 Distance Measured by the Radar Gauge Versus Target Permittivity for Three Different Notch Configurations on the 8 Inch Diameter Pipe . . 6

2 Distarice Measured by the Radar Gauge Versus Simulated Riser Diameter

3 Effect of Not Compensating for Added Weight on Level Measurements 18

4 Effect of Compensating for Added Weight in a Constant Volume on Level Measurements ................ 19

5 Effect of Volume Changes on Level Measurements . . . . . . . . 19

6 Precision of Laser Measuring Device Using Simulated Waste Tank Target ................... 26

7 Precision of Laser Measuring Device Using Simulated Waste Tank Target and a Folding Mirror ............... 27

8 Accuracy of Laser Measuring Device Using Simulated Waste Tank Target and a Folding Mirror ... . . . . . . . . . . . 28

9 Accuracy of Laser Measuring Device Using a White Diffuse Target and a Folding Mirror .................

10 Effect of Adding Resistance on Accuracy and Precision of Robertshaw

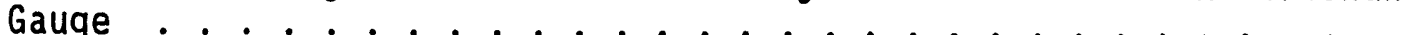

11 Accuracy of Sonic Sensor Using Dry Simulated Waste Material . . . 33

12 Accuracy of Sonic Sensor Using Wet Simulated Waste Material . . . 33

13 Accuracy of Sonic Sensor Using a Water Target ........... 34

14 Comparison of Different Level Measurement Instruments . . . . . . 41 


\section{BACKGROUND}

The surface level of the contents of the waste tanks has been measured for several years using a Food Instrument Corporation (FIC) electrical contact probe, manual-weighted tape, and zip cords. All of these devices exhibit problems in determining the distance to the waste surface. When the FIC probe contacts a liquid surface, electrical contact is registered and the liquid level is determined by measuring the amount of cable that was extended into the tank when electrical contact occurred. The desired accuracy for measuring the surface level is $\pm 6.4 \mathrm{~mm}$. ( $\pm 0.25 \mathrm{in}$.). The surface level is automatically recorded using the data acquisition system at predetermined times depending on the status of the tank. With the manual tape, a weight is placed at the end of a steel tape. The tape is lowered until a current meter connected between the tape and the riser shows a full-scale deflection. The level reading is taken from the tape. With the zip cord, the prestretched cord is lowered through a riser until the operator detects slack in the cord. The amount of cord that is released until slack is noted in the cable is used to determine the surface level.

One of the problems with measuring surface level using the contacting FIC probe, as well as the manual tape, is that crystals form on the probe or weight as it is withdrawn from the liquid material. This leads to inaccuracies in subsequent measurements made with the device. Another problem with the FIC probe and manual tape is that it cannot determine the level of solid materials if the surface dries out and it becomes nonconductive. Also, the weight of the probe or weight at the end of the FIC probe or manual tape eventualiy may pound a hole into the solid material, resulting in a false reading. Finally, because the dried-out sludge level can be so uneven and the salt cakes may shift, the probe may produce false readings of the actual (average) level of material in the tanks. The manual tape can also give inaccurate readings due to thermal expansion of the steel tape. The level measurement with the zip cord is dependent on the subjective determination of slack by the operator.

Thus, a better method needs to be found to determine the level of the surface. The purpose of this project was to evaluate and recommend some 
commercially available devices that could be used to replace the present FIC probe, manual tape, and zip cord. 


\section{TEST RESULTS}

\section{ENRAF-NONIUST 872 RADAR GAUGE}

Summary

The Enraf-Nonius model 872 radar gauge was retested to determine if the same effects that were reported previously (Peters, et. a1. 1992) using a 12in. diameter simulated riser would be seen with a 8-in. diameter simulated riser with a quarter wave notch at the end of it. The effect that was seen with the 12-in. diameter riser was that the distance to the target, as measured by the radar gauge, changed as the target properties changed. For the tests discussed in this section of the report, the simulated riser was an 8-in. diameter aluminum pipe, 20 feet long, and it was placed horizontally in front of the radar gauge antenna, as shown in Figure 1. The 8-in. pipe was tested with no notch at the end of it, as well as when a 0.295-in. and a 0.438-in. notch that was cut from one-half of the circumference at the end of the pipe. The results of the tests, which are discussed in this section of the report, indicate that the distance to the target did change as the target properties changed, even with the smaller diameter notched pipe. In addition, the output beam profile was measured for each of the three radar configurations--no pipe, an 8-in. diameter pipe, and a 12-in. diameter pipe in front of the antenna. The results indicate that the output beam is symmetric but has a higher peak power level and a smaller field of view, at a given target distance, when the radar beam propagates through the simulated risers. Notch Orientation

The first test was to determine if the orientation of the notch affected the amount of reflected signal received by the radar gauge from the end of the pipe. The notch depth for this test was 0.295 in. The results, shown in Figures 2 and 3 , show that a smaller signal (approximately $16 \mathrm{db}$ ) was reflected from the end of the pipe, which was at $20 \mathrm{ft}(6.1 \mathrm{~m})$, when the notch was orientated so that a line connecting the edges of the notch is parallel to the electric component of the radar beam (as shown in Figure 1) rather than perpendicular to the electric component. Notice that changing the orientation of the notch did affect the distance to the target measured by the radar 


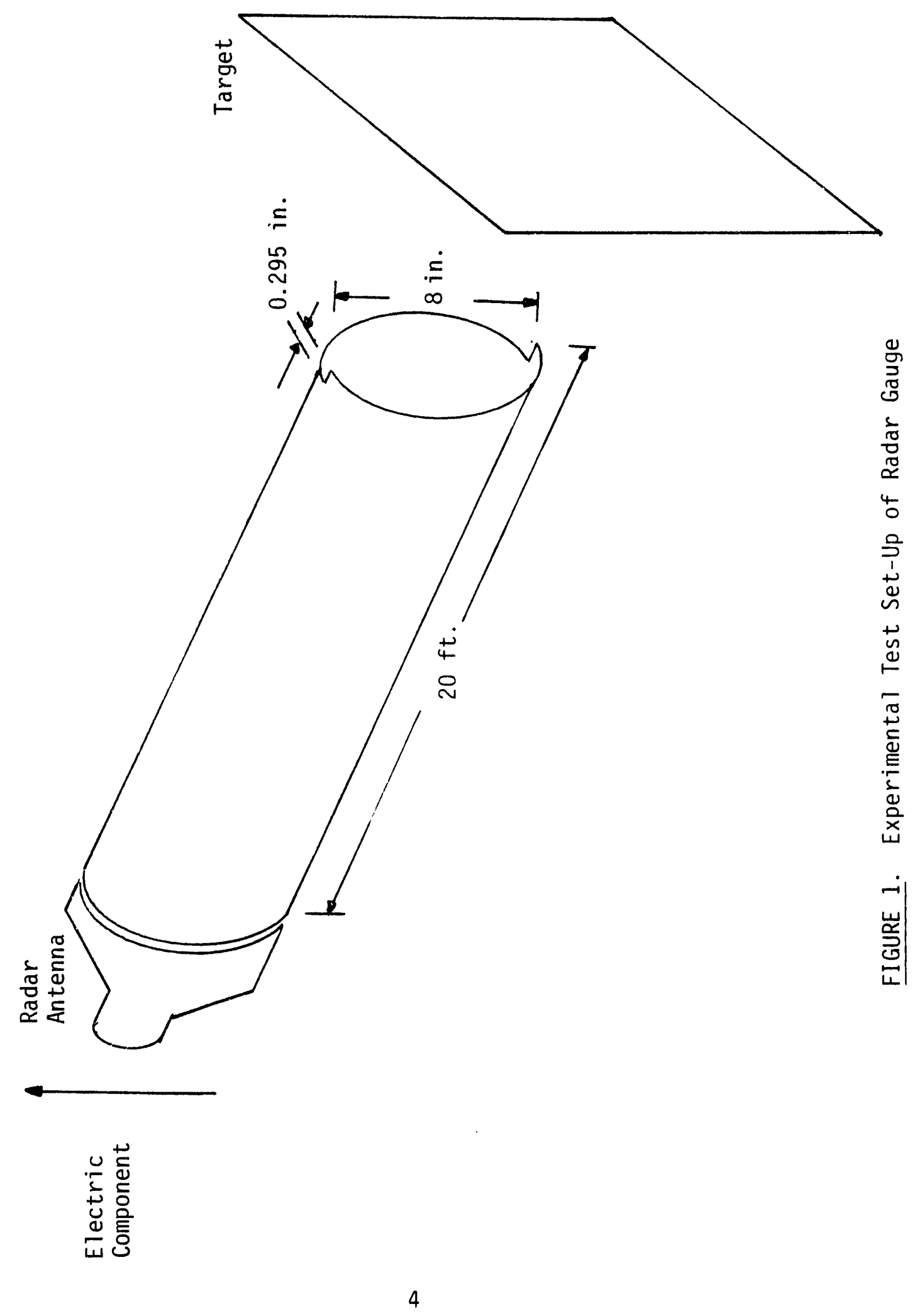




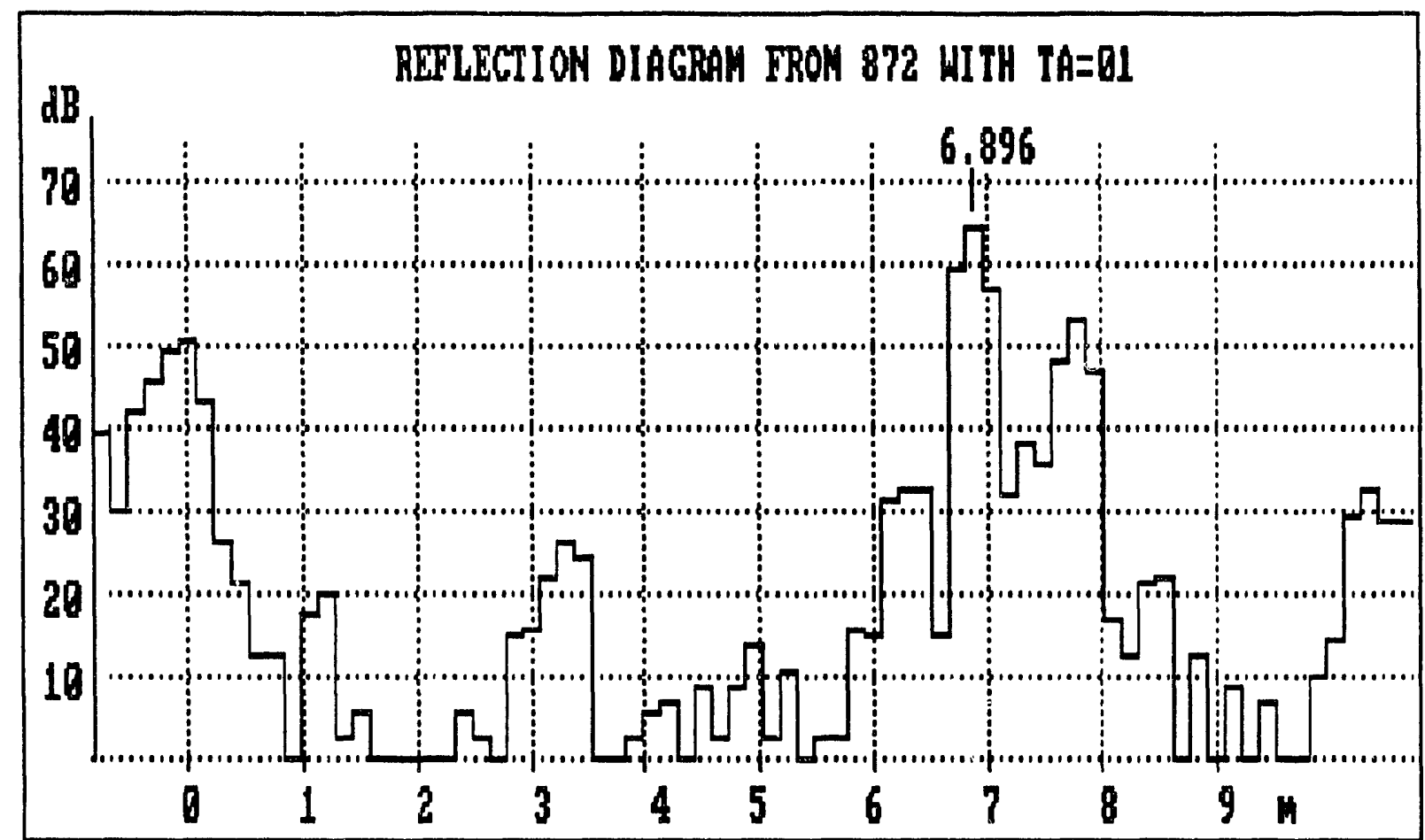

FIGURE 2. Reflection Diagram - Edge of 0.295 In. Notch Parallel to Electric Component

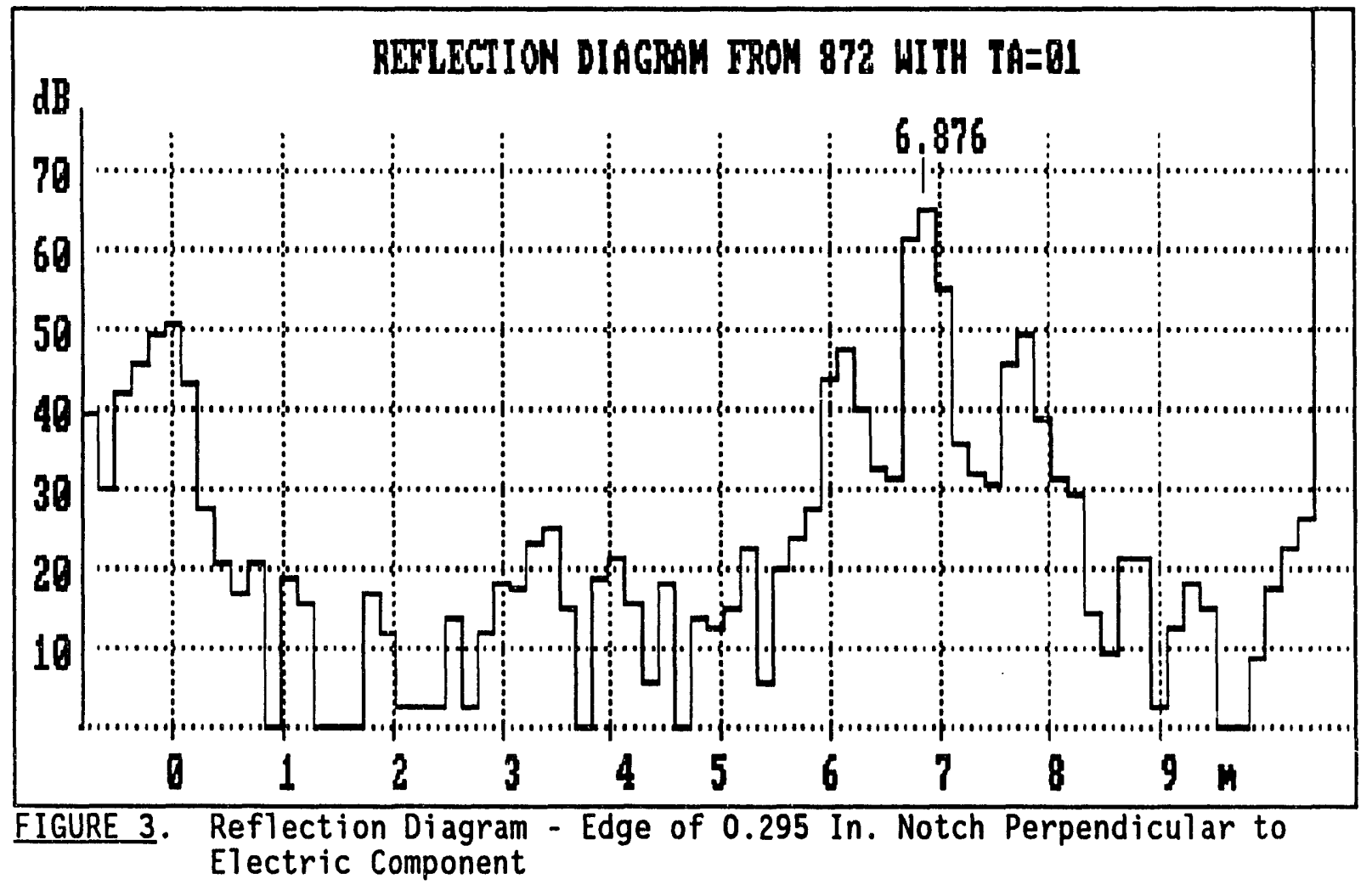


gauge. The target remained at $270 \mathrm{in}$. in both of these tests, yet the radar gauge measured a $0.79-i n .(0.02 \mathrm{~m})$ change in the distance to the target as the notch was rotated $90^{\circ}$. When the notch depth was increased to $0.438 \mathrm{in}$. (to match the notch in the stand pipe provided by Enraf-Nonius ${ }^{\mathrm{m}}$ ), the distance measured by the radar gauge changed $1.16 \mathrm{in} .(0.03 \mathrm{~m})$ as the notch was rotated $90^{\circ}$, as shown in Figures 4 and 5 . The amount of signal reflected from the end of the pipe was slightly higher (approximately $5 \mathrm{db}$ ) when the 0.438 -in. notch was parallel to the electric component than it was with the 0.295 in. notch. The signal was slightly lower (approximately $5 \mathrm{db}$ ) when the 0.438 -in. notch was perpendicular to the electric component than it was with the $0.295 \mathrm{in}$. notch.

\section{Change in Material Parameters}

Table 1 summarizes the results of the effect of changing the permittivity of the target on the distance to the target as measured by the radar gauge for the conditions when the 8-in. diameter pipe was not notched, and when it had a 0.295-in. and 0.438-in. notch at the end of it. The permittivity of the target was changed by using a dry glass target and then making it wet. The results are given for two different target distances--when the target was 1.5 in. and $18 \mathrm{in}$. from the end of the $20 \mathrm{ft}$. pipe. The values stated in Table 1 are corrected so the distance is measured from the antenna rather than the bottom of the tank, which is the normal measurement output for the radar gauge.

TABLE 1. Distance Measured by the Radar Gauge versus Target Permittivity for Three Different Notch Configurations on the 8-in. Diameter Pipe

\begin{tabular}{|c|c|c|c|c|c|c|}
\hline $\begin{array}{l}\text { Notch } \\
\text { Depth }\end{array}$ & 241.5 & $\begin{array}{r}\text { Dist } \\
\text {. Target }\end{array}$ & $\begin{array}{l}\text { e Measur } \\
\text { stance }\end{array}$ & $\begin{array}{l}\text { by the } \\
258 \mathrm{in}\end{array}$ & $\begin{array}{l}\text { ar Gauge } \\
\text { Target D }\end{array}$ & $\begin{array}{l}\text { in.) } \\
\text { tance }\end{array}$ \\
\hline (in.) & Dry & Wet & Change & Dry & Wet & Change \\
\hline No Notch & 243.20 & 243.52 & 0.32 & 259.51 & 259.14 & -0.37 \\
\hline 0.295 & 243.69 & 243.82 & 0.13 & 260.01 & 259.53 & -0.48 \\
\hline 0.438 & 243.85 & 244.75 & 0.90 & 259.40 & 259.04 & -0.36 \\
\hline
\end{tabular}




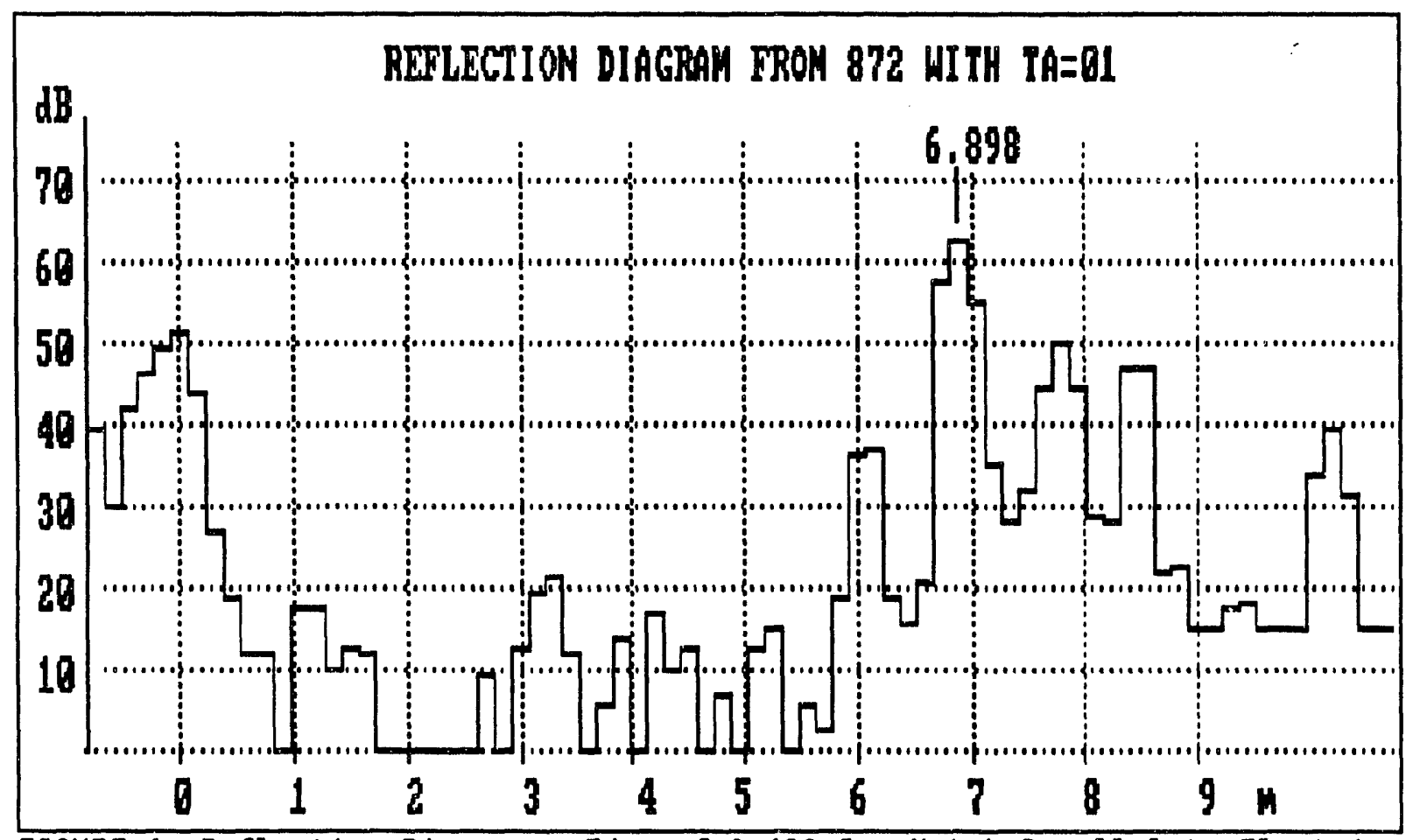

FIGURE 4. Reflection Diagram - Edge of 0.438 In. Not.ch Parallel to Electric Component

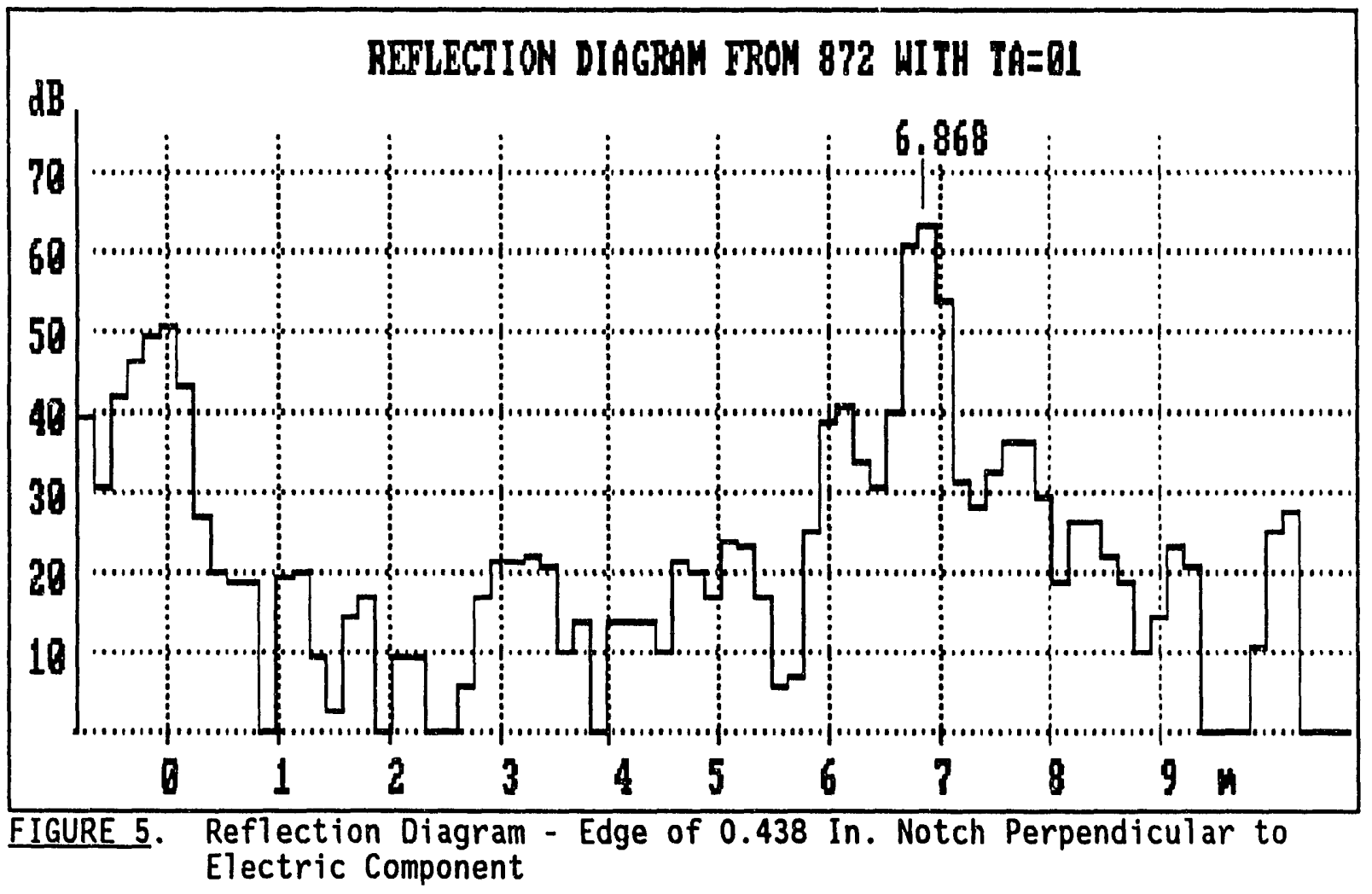




\section{Change in Riser Diameter}

The distance measured to the target by the radar gauge was also determined to be a function of the diameter of the riser. The results are shown in Table 2. For these tests, the target was located 21 feet from the radar gauge. This distance remained constant and the only change was placing various simulated risers in front of the radar gauge.

\section{Beam Profiles}

The profiles of the output beam one foot from the radar antenna, as well as one foot from the end of the 8-in. simulated riser $(21$ feet from the antenna) and one foot from the end of the 12-in. simulated riser (15.75 feet from the antenna) were measured and are plotted in Figures 6 through 11. The device that was used to determine the power output of the radar beam measured the electric component of the radar beam. It was placed on an $x y$ translation stage and the power of the beam at a given location was read on a meter. The power of the radar beam decreased quickly once the beam exited the pipe, and it was not possible to measure the beam profile for the three test conditions (no pipe in front of the antenna, as well as a 8-in. and 12-in. diameter pipe in front of the antenna) at a constant distance, e.g., 21 feet, from the antenna. The results of this test indicate that the beam profiles were symmetric, and the peak power increased when the radar beam propagated through the riser. The beam profile is narrower as the diameter of the simulated riser decreased (the volume in the beam profile is 489 units with no pipe in front of the antenna, 330 units with an 8-in. pipe, and 402 units with a 12in. pipe). This means the field of view is smaller with the 8-in. pipe. For

TABLE 2. Distance Measured by the Radar Gauge Versus Simulated Riser Diameter

\begin{tabular}{l|c|c}
$\begin{array}{c}\text { Pipe } \\
\text { Diameter }\end{array}$ & $\begin{array}{l}\text { Distance Measured } \\
\text { By Radar Gauge (in.) }\end{array}$ & $\begin{array}{l}\text { Change } \\
\text { (in.) }\end{array}$ \\
\hline No Pipe & 251.56 & Base \\
$12 \mathrm{in.}$ & 252.17 & 0.61 \\
$8 \mathrm{in.}$ & 253.75 & 2.19
\end{tabular}




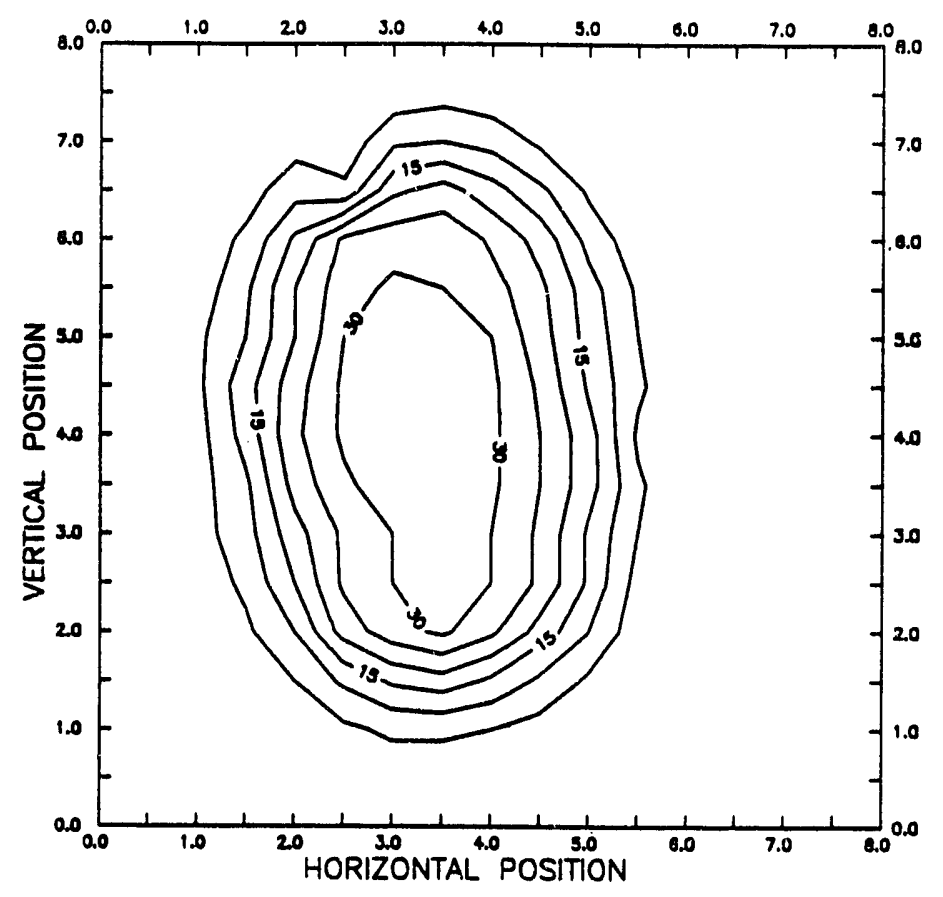

FIGURE 6. Beam Topography 1 Foot From Antenna

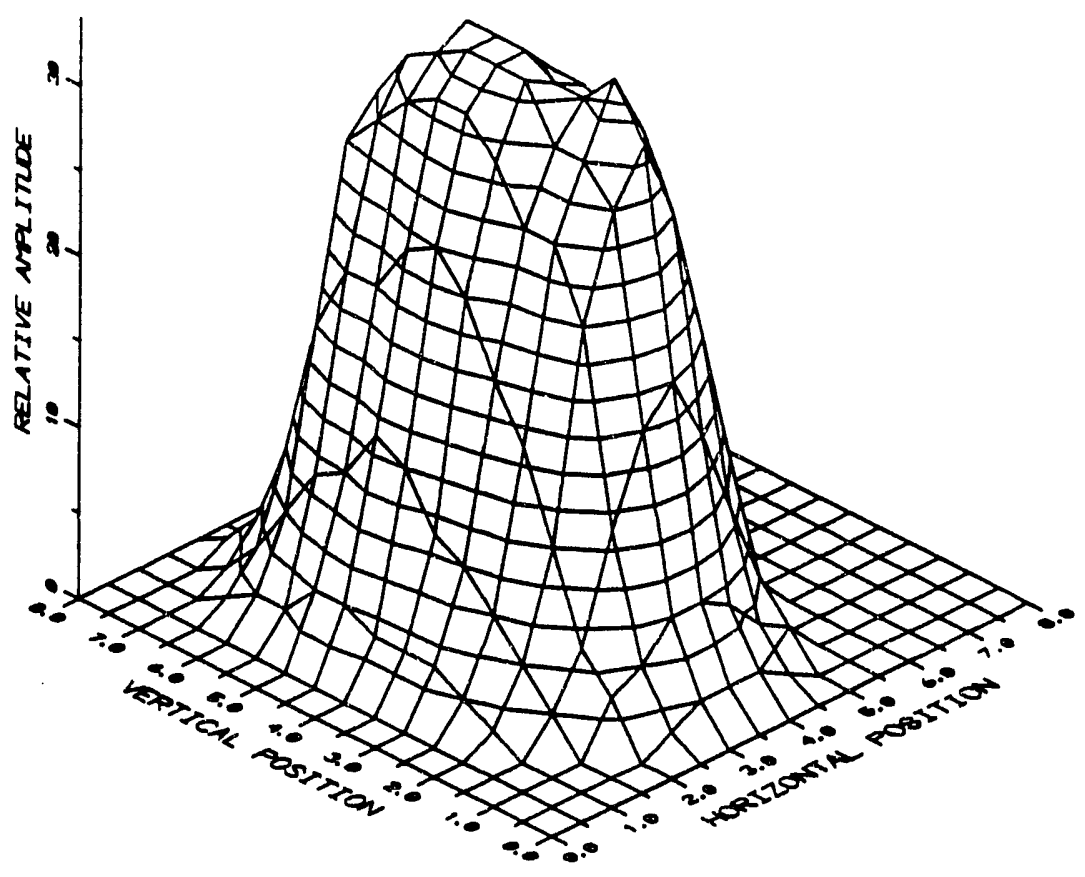

FIGURE 7. Beam Profile 1 Foot From Antenna 


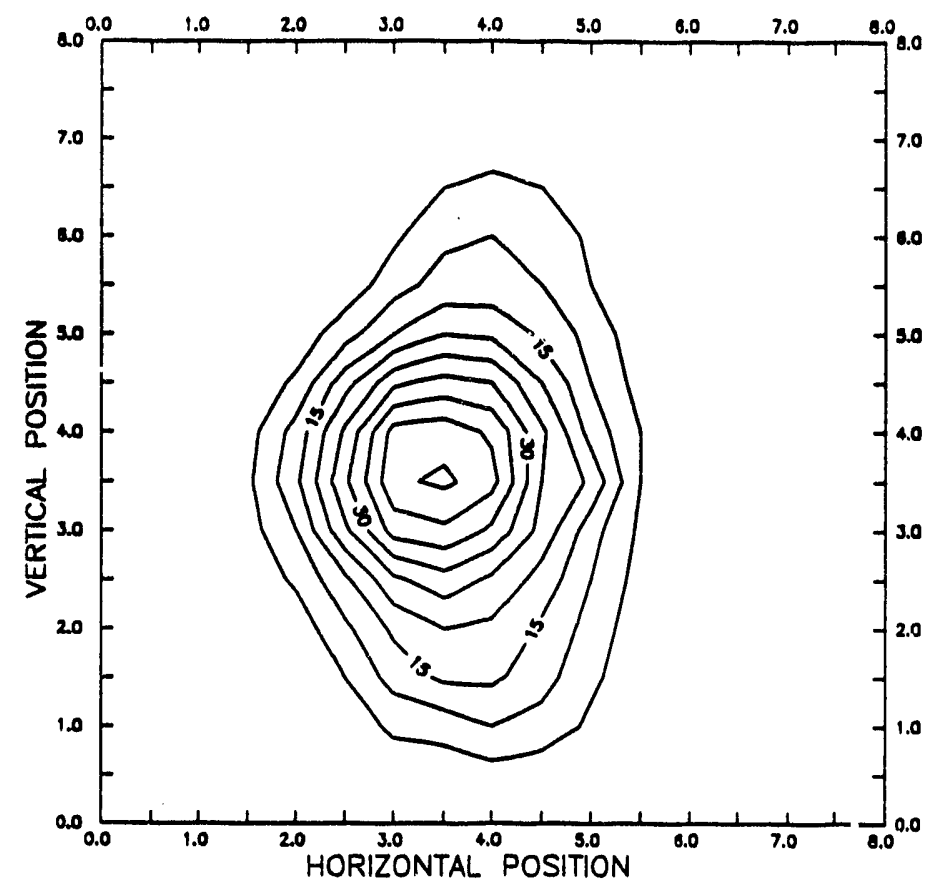

FIGURE 8. Beam Topography 1 Foot From 8-in. Pipe

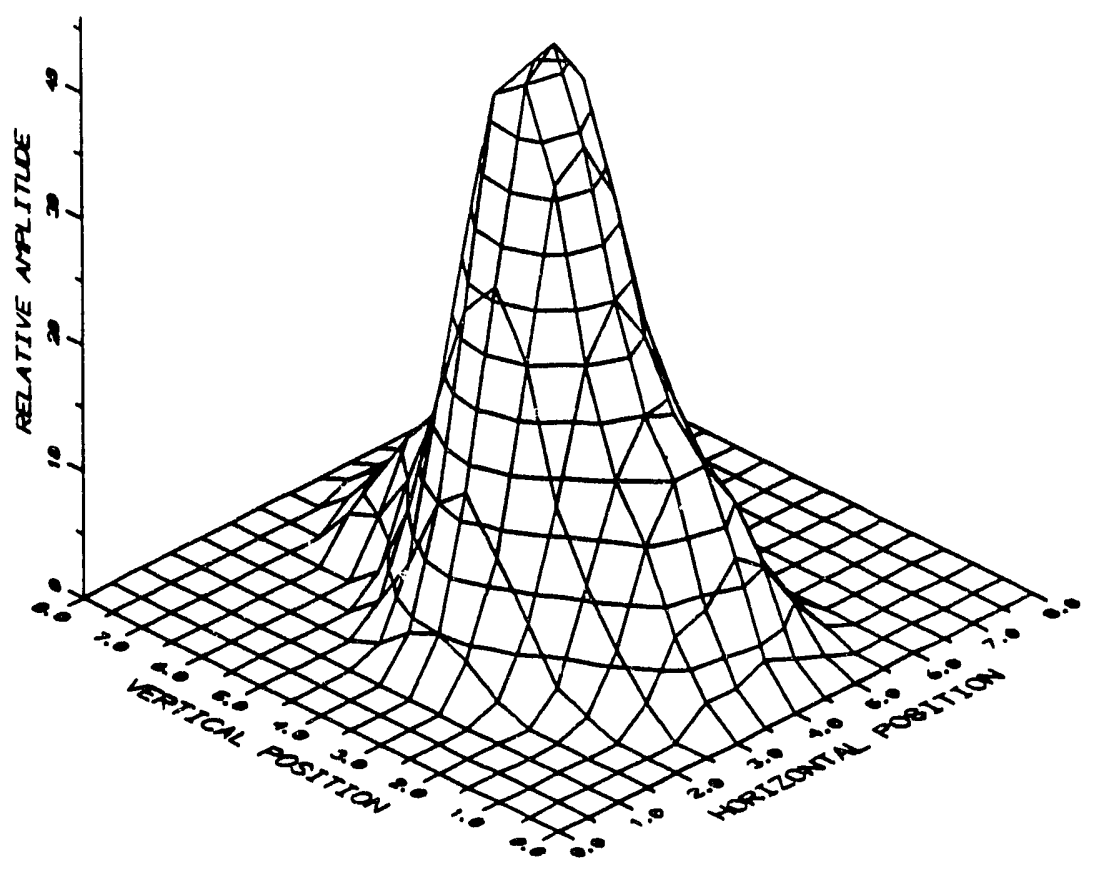

FIGURE 9. Beam Profile 1 Foot From 8-in. Pipe 


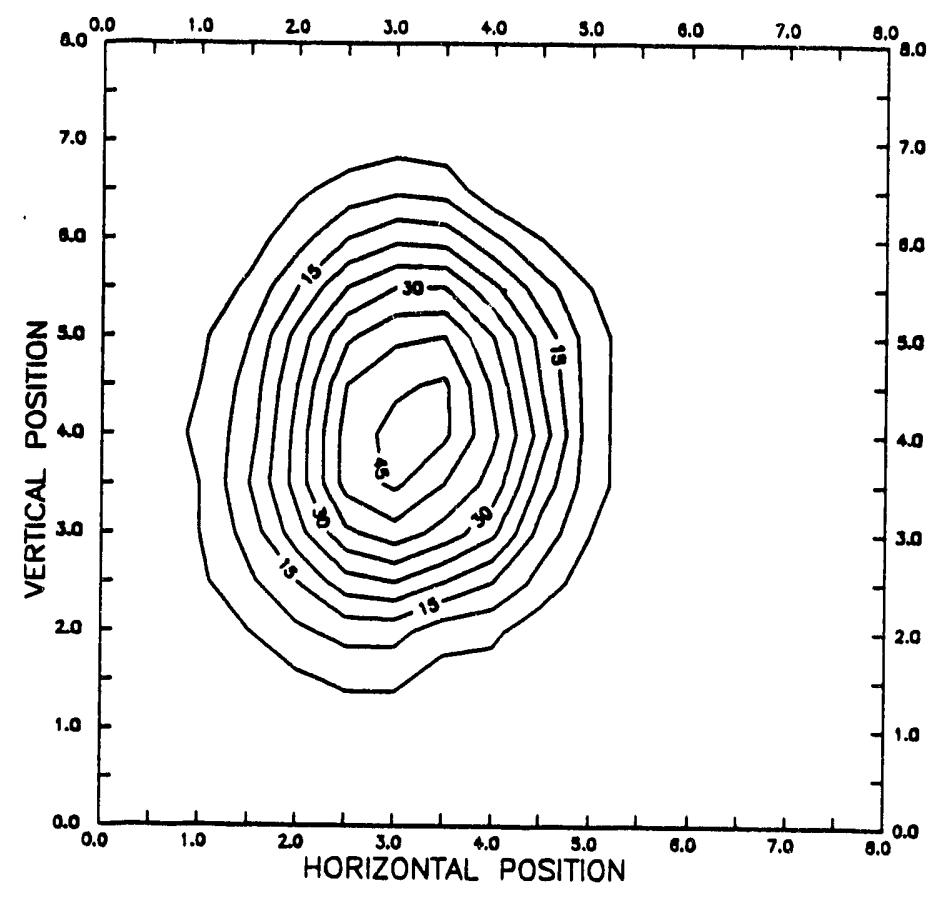

FIGURE 10. Beam Topography 1 Foot From 12-in. Pipe

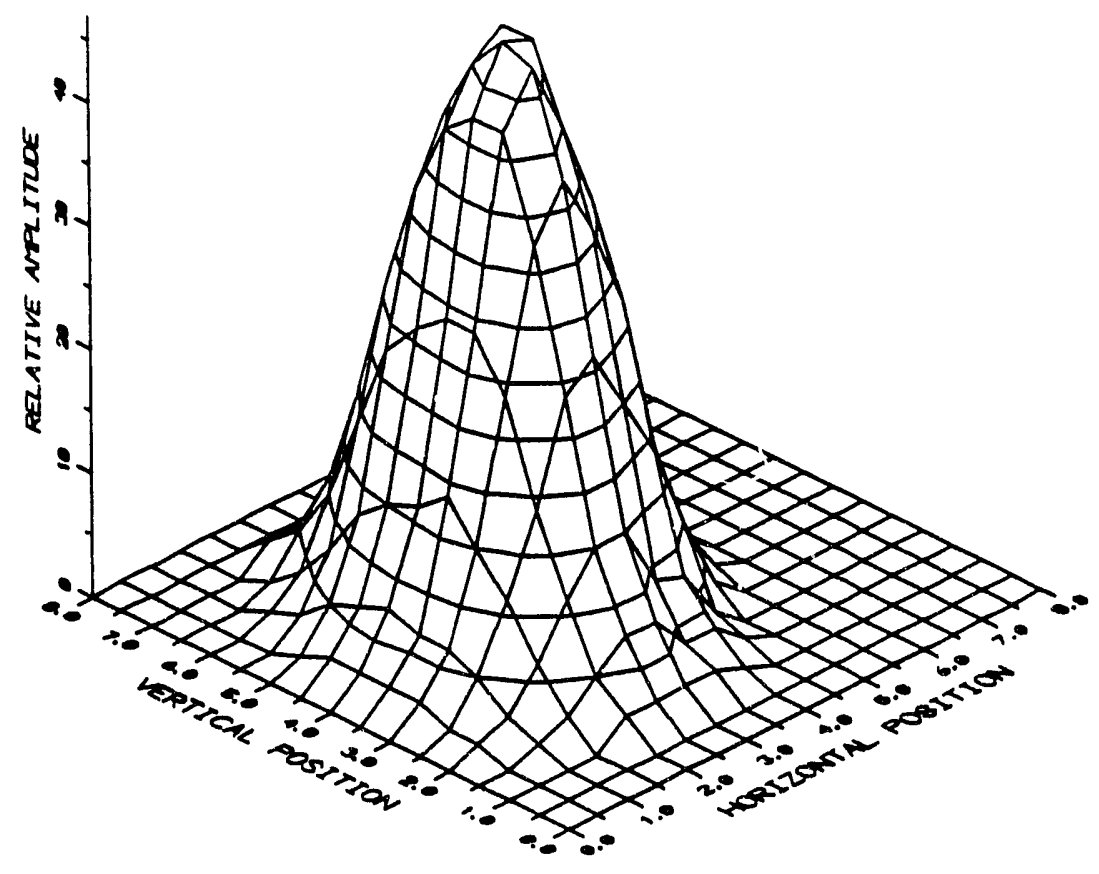

EIGURE 11. Beam Profile 1 Foot From 12-in. Pipe 
example, these tests indicated that the field of view of the radar beam at 21 feet is only $6 \times 4 \mathrm{in}$. when it propagates through the 8 -in. diameter riser which is 20 feet long. The longest dimension is parallel to the electric component of the radar beam. Previous tests indicated that at 21 feet from the antenna, the field of view is $17 \times 13 \mathrm{in}$. for the 12 -in. diameter riser which is 14.75 feet long, and it is $53 \times 36$ in. when no simulated riser is placed in front of the antenna.

\section{Reflection Diagrams}

Testing indicated that inconsistent signals are displayed from the reflection diagrams. The distance displayed by the remote indicator of the radar gauge was consistent between consecutive tests, and the distance displayed by the program before the reflection diagram is displayed was usually, but not always, consistent, but the peak signals displayed by the reflection diagram were not consistent from one test to the next test. This is illustrated in Figures 12 through 15. The test was performed with the glass target at 21 feet from the antenna of the radar gauge with no simulated riser in place. In Figure 12, a reflection diagram is shown that has the expected profile, i.e., only one large signal at the target location $(6.381 \mathrm{~m})$. The test was repeated, with nothing changing other than restarting the program which runs the reflection diagram. The result is shown in Figure 13, and now a large signal is occurring at approximately $4.75 \mathrm{~m}$. In addition, at times the system would miss the target, as shown in the reflection diagrams in Figures 14 and 15. The same effect was seen with both the 8-in. and 12-in. riser in place, although the inconsistency seemed to be most prevalent with the 8 -in. riser. This result indicates that the reflection diagrams cannot be used to characterize the internal properties of the waste, and more than one reflection diagram needs to be used in order to characterize the effect of a riser and its surroundings on the signal received by the radar unit. 


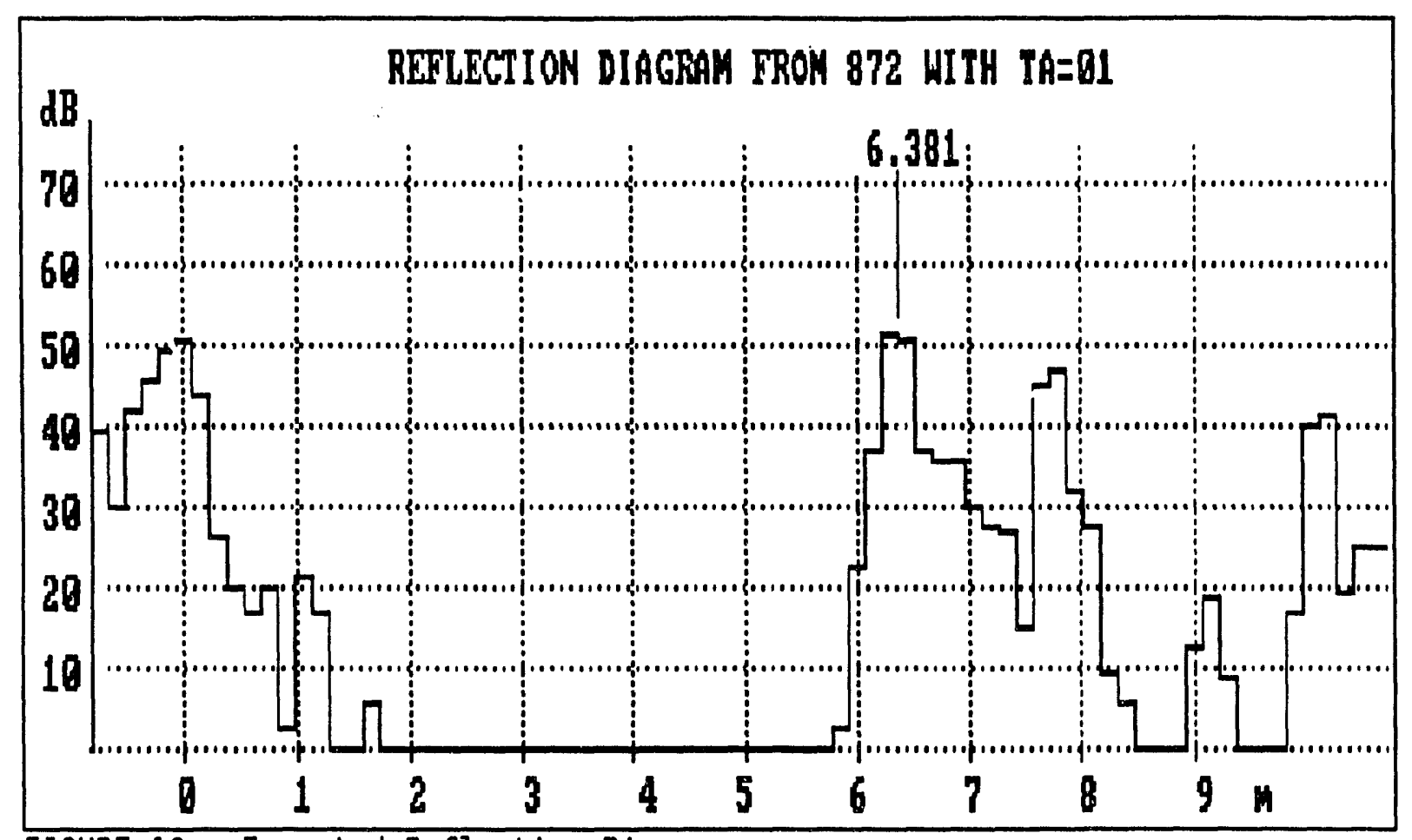

FIGURE 12. Expected Reflection Diagram

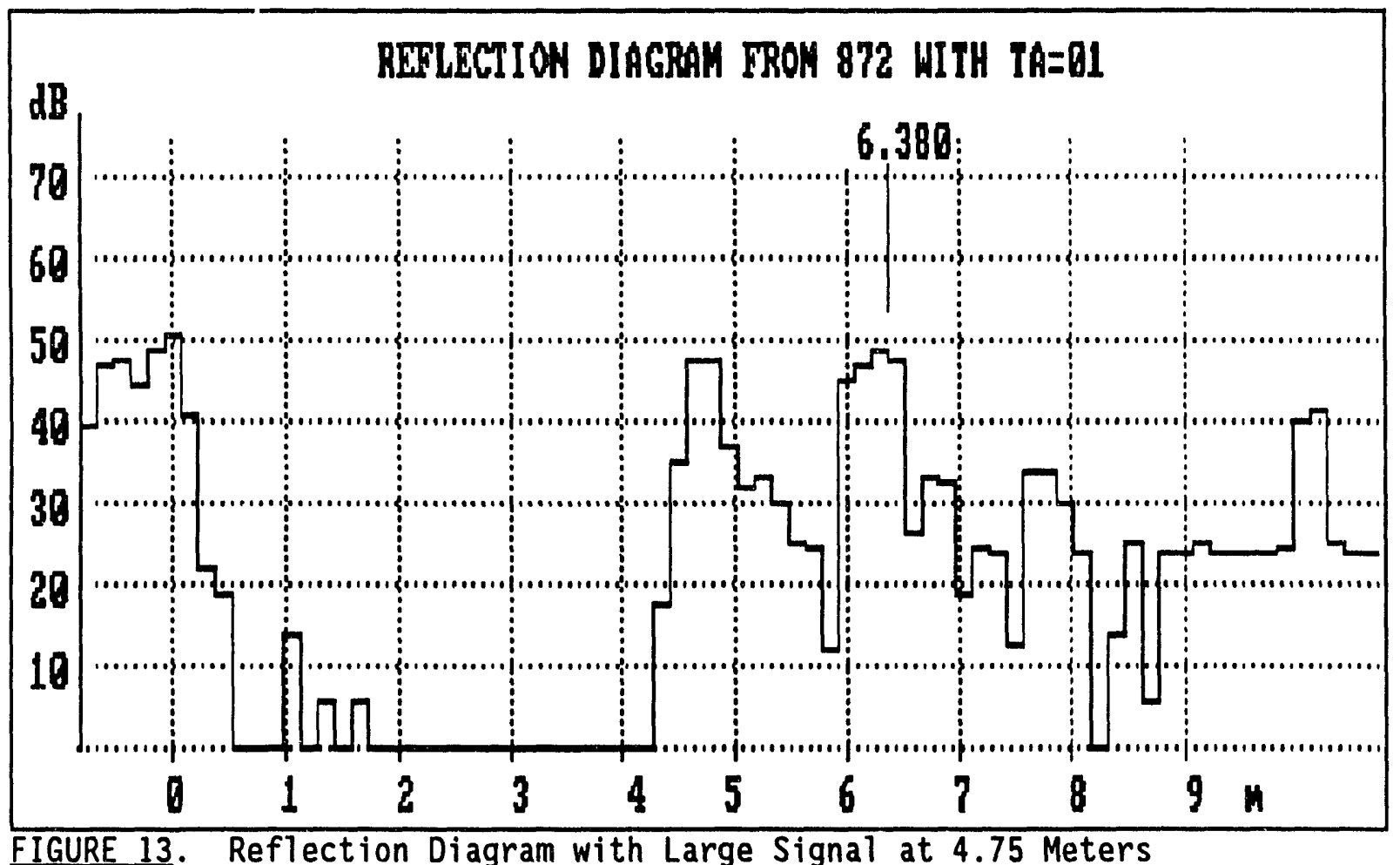



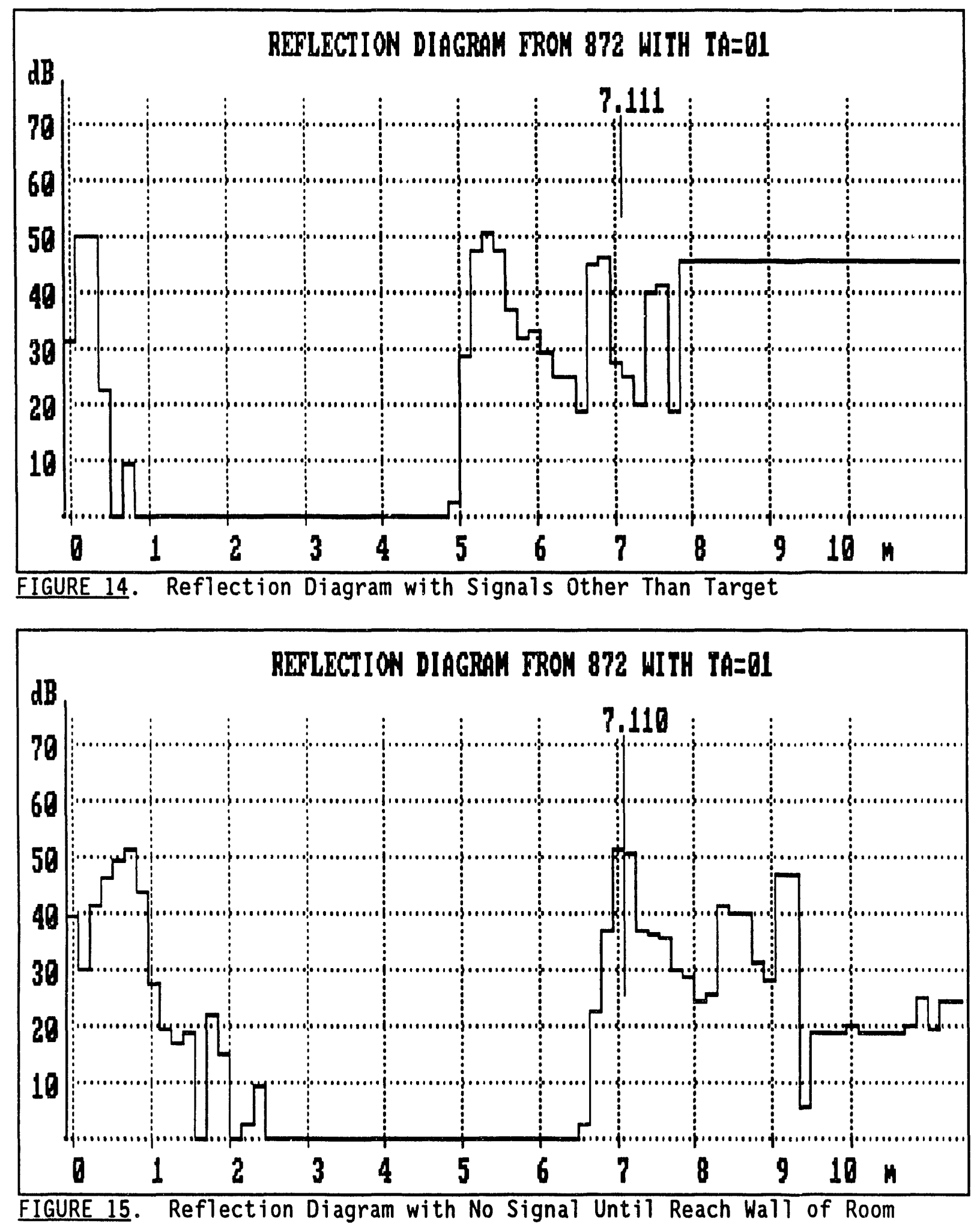


\section{ENRAF-NONIUST 854 ADVANCED TECHNOLOGY GAUGE}

Summary

The Enraf-Nonius' 854 Advanced Technology Gauge (ATG) was tested to determine whether it could be used to measure the distance to the surface in the waste tanks. The ATG gauge operates by detecting the change in the buoyancy of a weight (displacer) and matching the apparent weight of the displacer to a preset value. The displacer is connected to the drum of the instrument by a stainless steel wire, $0.007 \mathrm{in}$. in diameter. When the apparent weight of the displacer matches the preset weight, the position of a stepper motor, i.e., the amount of stainless steel wire that has been released from the drum, determines the distance to the surface leve1. The ATG gauge was designed for a liquid surface, but could be used to determine the distance to a flat solid surface. The advantage of this gauge over the FIC gauge presently used in the waste tanks is that the detection of the surface level is not dependent on making electrical contact. In addition, providing the displacer has a large enough volume or the difference in the density of the liquids is large enough, the ATG gauge can measure the level of the interface of a liquid (or solid) that is beneath another liquid of lower density. The ATG gauge is certified to be explosion proof.

The normal operating mode for the ATG gauge is for the displacer tc remain in the fluid, thus providing a continuous readout of the distance to the surface. If crystals begin to grow on the displacer, the gauge can be lifted out of the liquid, the displacer reweighed using the ATG gauge, and the set-up parameters for the gauge changed to compensate for the added weight of the crystals. The testing indicated that the gauge does accurately compensate for added weight. However, this is not done automatically by the gauge, and the weight compensation would have to be accomplished by a controlling computer program. Also, the ATG gauge only allows the apparent weight of the displacer to vary between $35 \mathrm{gm}(0.08 \mathrm{lbs}$.$) and 300 \mathrm{gm}(0.66 \mathrm{lbs}$.$) , which$ means if the weight of the displacer and the crystals exceed $300 \mathrm{gm}(0.66$ lbs.), then a different buoyancy force (which is the difference between the apparent weight and the actual weight of the displacer) will have to be used to determine the level of the surface, which, of course, changes the level measurement. In addition, when crystals are added to the displacer, they can 
change the volume of the displacer, which may affect its buoyancy, and hence affect the distance to the liquid surface measured by the gauge. Depending on the density of the crystals relative to the material in the tank, the gauge reading could increase, decrease, or remain unaffected by the additional volume added by the crystals. The effect of changes of the volume of the displacer on the measured distance to the surface was investigated during this vesting.

In its normal operating mode, the ATG gauge could not be used in a tank with salt cakes or surface motion in it, because if the displacer is moved, the distance to the surface will increase. In order to measure a surface that has sait cakes or exhibits motion, the operating mode of the ATG gauge would have to be modified to a sampling mode where the dis,placer is normally out of the fluid and lowercd onto the surface when a measurement is tiken. Testing indicated on?y a $0.03-i n$. change in the measured distance to the surface when the displacer was placed in a tank with water circulating at $5 \mathrm{gal} . / \mathrm{min}$.

In the system that was tested, the measured distance to the surface would be affected by changes in the air temperature above the surface. If the temperature in the tank changes greatly, the stainless steel wire would expand or contract, which would result in a change in the measured level to the surface. Enraf-Nonius"m sells a module for tile ATG gauge for temperature compensation, but this module was nct part of the system that was tested. Test Set-Up

The ATG gauge was set up as shown in Figure 16. Except for the tests conducted with the stainless steel displacer discussed in a separate section of this report, the displacer (part number 0815344) had a $90 \mathrm{~mm}$ (3.54 in.) $0 . D ., 64 \mathrm{~cm}^{2}\left(9.92 \mathrm{in}^{2}\right)$ surface area, $110 \mathrm{~cm}^{3}\left(6.71 \mathrm{in}^{3}\right)$ bolume and weighed approximately $223 \mathrm{gm}(0.49 \mathrm{lbs}$.). The tank contained water, $3.4 \mathrm{in}$. deep. The gauge was located about $33 \mathrm{in}$. from the surface of the water. The ATG gauge measures the distance from ine bottom of the tank to the surface level. For these tests, the bottom of the tank was set at $35 \mathrm{ft}$. (420 in.). In order to avoid confusion, the measurements are converted so that the value is taken from the top of the tank (which was frogrammed to be approximately $4.75 \mathrm{in}$. from the bottom of the ATG gauge). 


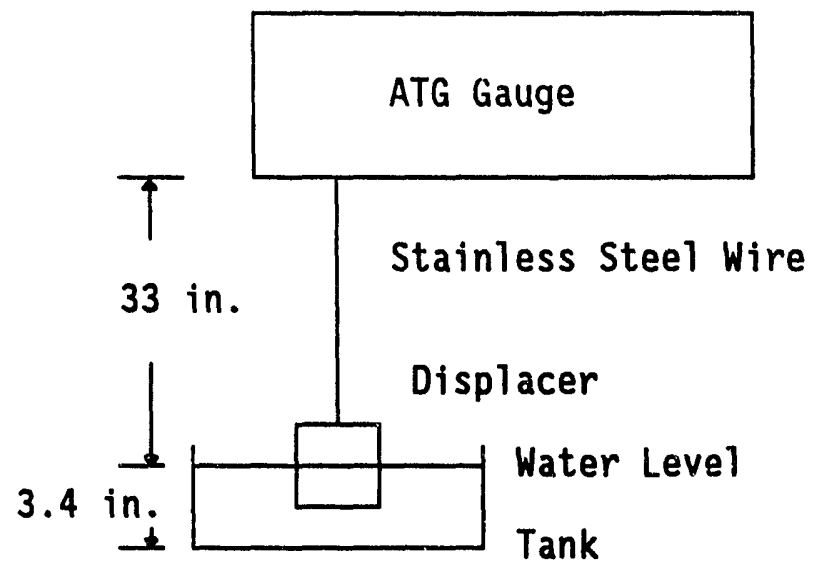

FIGURE 16. Experimental Test Set-up of ATG

\section{Repeatability}

The repeatability of the ATG gauge was tested by reading the gauge to determine the distance to the water, lifting the displacer above the water, then allowing the gauge to redetermine the distance to the water. The gauge read the distance to the water with a repeatability of $\pm 0.012 \mathrm{in}$. (one standard deviation).

The repeatability of the ATG gauge to read the surface level over a period of time was tested by leaving the displacer in the water overnight without changing the test set-up. The measured distance to the liquid level varied only 0.04 in. after 17 hours.

Adding $0.1 \mathrm{in}$. water to the tank, the gauge indicated a 0.12 -in. change in the distance to the liquid surface.

One of the features of this device is its ability to measure the level of liquids that are underneath, i.e., have a higher density, other liquids. A fluid was set up that contained oil (density $0.93 \mathrm{gm} / \mathrm{cm}^{3}$ or $58 \mathrm{lb} / \mathrm{ft}^{3}$ ) at the top, water (density $1.0 \mathrm{gm} / \mathrm{cm}^{3}$ or $62.4 \mathrm{lb} / \mathrm{ft}^{3}$ ) in the middle, and molasses (density $1.29 \mathrm{gm} / \mathrm{cm}^{3}$ or $80.5 \mathrm{~b} / \mathrm{ft}^{3}$ ) at the bottom. Determining the level of these liquids five times, the neasured distance to each liquid varied \pm 0.01 in. for the air/oil interface, $\div 0.03 \mathrm{in}$. for the $0 i 1 /$ water interface, and $\pm 0.03 \mathrm{in}$. for the water/molasses interface (one standard deviation). 


\section{Weight Compensation}

This test was conducted to determine how the distance to the surface level changed as the weight of the displacer changed. In the first set of tests, weights were added to the top of the displacer and the apparent weight of the displacer (denoted in the ATG program as parameter S1) was kept at 208 gm (0.46 lbs.). This test would simulate a condition in which crystals were unknowingly being formed on the displacer. The results are shown in Table 3 and indicate that the gauge will misread the distance to a surface with a density similar to water at a rate of $0.0068 \mathrm{in./} \mathrm{gm}(3.09 \mathrm{in} / \mathrm{lb})$.

Placing a $50 \mathrm{gm}(0.11 \mathrm{lb}$.$) weight on the displacer and changing the$ apparent weight (S1) so that the buoyancy force remains at $15 \mathrm{gm}(0.03 \mathrm{lb}$.) resulted in the ATG determining the distance to the surface to be $28.05 \mathrm{in}$., which is 0.01 in. different than the base measurement in Table 3. Thus, if the weight of the displacer changes and the apparent weight is subsequently changed so the buoyancy force remains constant, the gauge will correctly measure the distance to the liquid. It should be noted that the ATG gauge only allows the displacer apparent weight to vary between 35 and $300 \mathrm{gm}(0.08$ to $0.66 \mathrm{lb}$.); so if the crystals add a substantial weight to the displacer, it may not be possible to compensate for it without increasing the difference between the apparent weight and the actual weight. This is what occurred in the next test.

IABLE 3. Effect of Not Compensating for Added Weight on Level Measurement

\begin{tabular}{|c|c|c|c|}
\hline (gm & (1b.) & $\begin{array}{l}\text { Level } \\
\text { (in.) }\end{array}$ & $\begin{array}{l}\text { Change } \\
\text { (in.) }\end{array}$ \\
\hline $\begin{array}{r}0 \\
20 \\
25 \\
30 \\
35 \\
40 \\
45 \\
50\end{array}$ & $\begin{array}{l}0.00 \\
0.04 \\
0.06 \\
0.07 \\
0.08 \\
0.09 \\
0.10 \\
0.11\end{array}$ & $\begin{array}{l}28.04 \\
28.16 \\
28.18 \\
28.22 \\
28.24 \\
28.28 \\
28.34 \\
28.39\end{array}$ & $\begin{array}{l}\text { Base } \\
0.12 \\
0.14 \\
0.18 \\
0.20 \\
0.24 \\
0.30 \\
0.35\end{array}$ \\
\hline
\end{tabular}


In the next test, weight was added to the bottom of the displacer inside a constant volume container. The container was needed because the weights occupied different volumes and we wanted to isolate weight changes from volume changes. The container consisted of a $100 \mathrm{ml}$ (3.38 0z.) plastic beaker attached to the displacer. This test would determine if the gauge can compensate for the weight of salt crystals added to the bottom of the displacer (ignoring the change in volume). The buoyancy force was increased to 31 grams $(0.07$ lb.) because the weight of the displacer and the plastic beaker and the $100 \mathrm{gm}(0.22 \mathrm{lb}$.) weight exceeded the $300 \mathrm{gm}(0.66 \mathrm{lb}$.$) limit$ for setting the apparent weight. The results are shown in Table 4 and indicate that the gauge will compensate for the added weight on the bottom of the displacer providing the apparent weight is changed.

\section{Volume Compensation}

Different size beakers were attached to the bottom of the displacer to simulate different volumes that may get attached to the displacer. For these tests, the buoyancy force was again set for $15 \mathrm{gm}(0.03 \mathrm{lb}$.$) . The results,$ shown in Table 5, indicate that the ATG gauge was not able to compensate for the changing volumes, and that a substantial error occurs in the level measurement as the volume changes.

TABLE 4. Effect of Compensating for Added Weight in a Constant Volume on Level Measurement

\begin{tabular}{|c|c|c|c|}
\hline \multicolumn{2}{|c|}{$\begin{array}{l}\text { Added } \\
\text { Weight } \\
\text { (gm) (1b) }\end{array}$} & $\begin{array}{l}\text { Level } \\
\text { (in.) }\end{array}$ & $\begin{array}{l}\text { Change } \\
\text { (in.) }\end{array}$ \\
\hline $\begin{array}{r}0 \\
50 \\
100\end{array}$ & $\begin{array}{l}0.00 \\
0.11 \\
0.22\end{array}$ & $\begin{array}{l}25.78 \\
25.82 \\
25.83\end{array}$ & $\begin{array}{l}\text { Base } \\
0.04 \\
0.05\end{array}$ \\
\hline
\end{tabular}

TABLE 5. Effect of Volume Changes on Level Measurement

\begin{tabular}{cc|c|c} 
(m) & $\begin{array}{c}\text { Added } \\
\text { Volume } \\
\text { (oz) }\end{array}$ & $\begin{array}{l}\text { Level } \\
\text { (in.) }\end{array}$ & $\begin{array}{l}\text { Change } \\
\text { (in.) }\end{array}$ \\
\hline 0 & 0.00 & 27.59 & Base \\
15 & 0.51 & 26.87 & 0.72 \\
100 & 3.38 & 25.56 & 2.03
\end{tabular}


The error in the level measurement is given by:

$$
\Delta h=\frac{V_{b}}{A}\left(\frac{\rho_{b}}{\rho_{c}}-1\right)
$$

where $\Delta h=$ error in level measurement

$V_{b}=$ volume of the salt crystals added to the displacer

$A=$ area of weight immersed in the surface material

$\rho_{b}=$ density of the salt crystals added to the displacer

$P_{c}=$ density of the surface material

Note that if $p_{b}=P_{c}$, i.e., the salt crystals have the same density as the surface material, there is no error in the level measurement. Also note that a long thin salt crystal that forms on the displacer will create a larger error in the measured distance to the surface than a thin salt crystal with the same volume that forms over a large diameter displacer.

Coating Test

Investigations were conducted in this study to determine if a coating can be applied to the displacer to minimize the growth of crystals on the displacer. A polyethylene coating, of various thicknesses, was applied to stainless steel coupons, both polished and unpolished. In addition, silver microballoons and stainless steel powder was added to the polyethylene coating to determine if the coating could be made conductive (which is needed for the FIC or Robertshaw gauge). The coupons were dipped in a simulated waste tank material (the chemical make up of the simulant is given in Appendix A), which had the consistency of a soft milkshake, using a cycle of one minute in the simulant and ten minutes out of the simulant. This cycle was continued for eight hours. The results are shown in Figure 17a and 17b. No difference was noted in the build up of crystal growth on the polyethylene coated samples compared to the uncoated samples, nor was there any difference noted between the polished and the unpolished samples. The addition of silver and stainless steel to the coating did not make them more conductive than the coupons with only polyethylene coating. The rate of build up of the coating on the coupons was substantially reduced when the polyethylene coated sample was left continuously in the simulated waste, as sown in Figure 17c. A small im of 


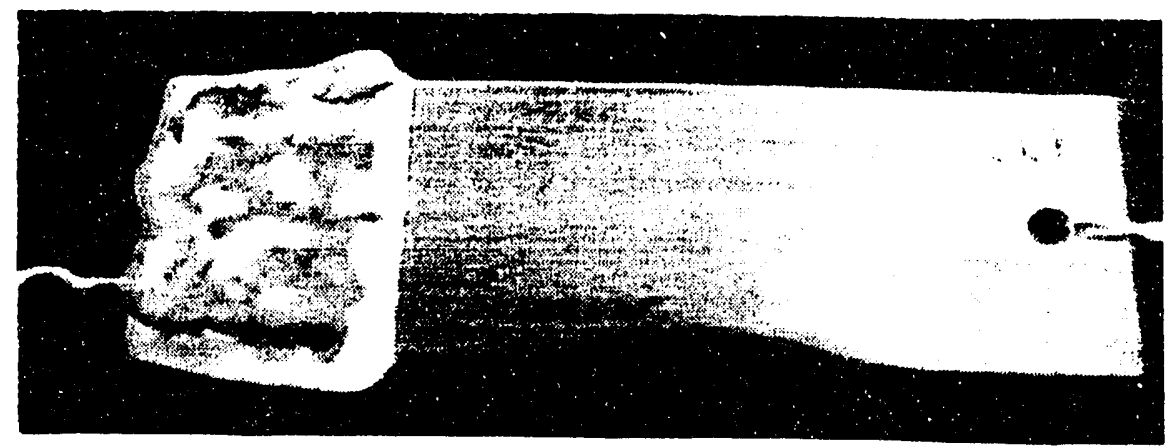

FIGURE 17a. Results of Dip Test with No Coating on Coupon

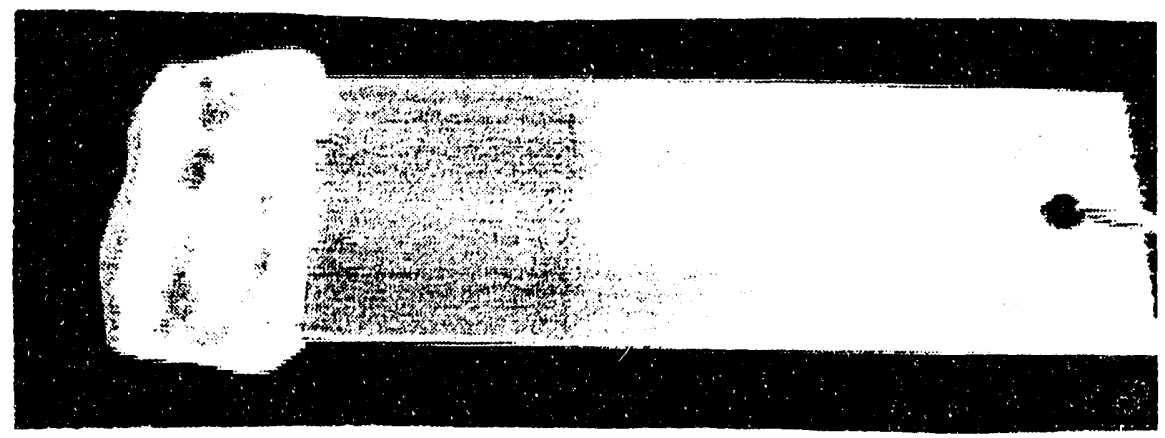

FIGURE 17b. Results of Dip Test with Polyethylene Coating on Coupon

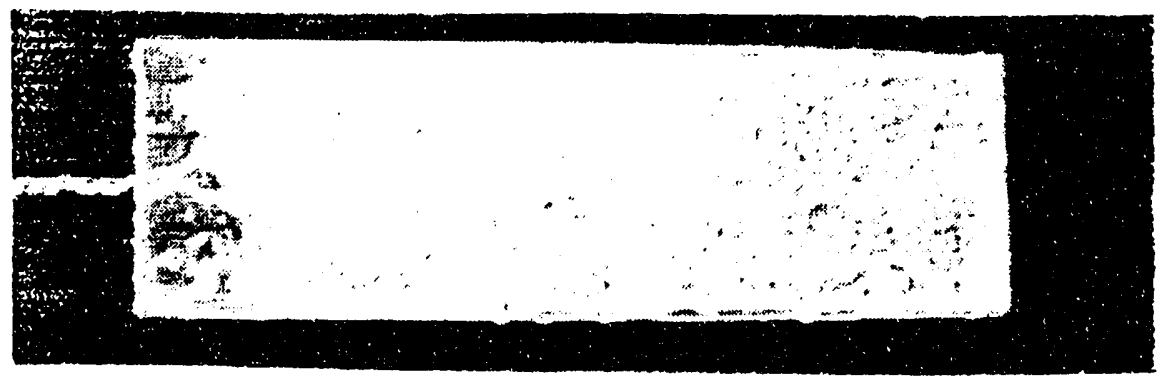

FIGURE 17c. Results of Continuous Submersion with No Coating on Coupon

FIGURE 17. Photographs of Results of Coating Test 
coating was observed after the coating was in the simulated waste for about one week. This implies that the coating build up is due to the drying process when the coupon is removed from the waste material.

\section{Surface Motion}

If the displacer moves horizontally, as would occur if the surface moves or the displacer is caught by a salt cake, then the distance measured by the ATG gauge will increase. The error in the level measurement is given by the formula:

$$
\Delta h=d(1-\cos a) / \cos a
$$

where $\Delta h=$ error in the level measurement

$d=$ vertical distance to the surface level

$a=$ angle between vertical distance to the surface and the stainless steel line

If the surface is twenty feet from the gauge, and an acceptable error in measuring the distance to the level is $0.05 \mathrm{in}$, then the maximum angle that can be tolerated is $1.17^{\circ}$. This means the displacer can only move 4.9 in. horizontally. The only way to compensate for surface motion is to have the displacer normally out of the fluid and have it lowered onto the surface when a surface level measurement is to be taken, as is presently being done for the FIC gauges. However, salt cakes that move directly under the measuring device will result in inconsistent readings.

A quick test was performed to determine the motion of the displacer in a turbulent fluid by circulating water at $5 \mathrm{gal} . / \mathrm{min}$. in a tank approximately $11.5 \times 13.5 \mathrm{in}$. The displacer remained stationary, and the measured distance to the surface varied only 0.03 in. maximum. It is necessary for the top of the displacer to be tapered so waste tank material will not sit on top of the displacer, which would add to its weight and result in an error in the level measurement, as discussed previously.

\section{Temperature}

If the stainless steel wire expands, it also will result in a change in the measured distance to the surface. We placed a heat gun on a small section of the wire and were able to change the distance to the surface by 0.01 in. 
The expansion coefficient of stainless steel is approximately $9.6 \times 10^{-6} / \circ \mathrm{F}$. This means if the wire is $20 \mathrm{ft}$. long, then a change of approximately $22 \circ \mathrm{F}$ in the air in the waste tank will result in a $0.05 \mathrm{in}$. change in the level measurement.

\section{Solid Surface}

The ATG gauge was primarily designed to be used to measure the distance to a liquid surface. However, it can be used to measure the distance to a solid surface. In this case, the apparent weight (S1) would be set a few grams below the weight of the displac:r. As soon as the displacer reaches the solid surface, there will be some slack in the line, and the distance to the surface could be determined. The solid surface would have to be flat so the displacer would not slide around, which would give inconsistent readings to the surface.

\section{Stainless Steel Displacer}

The tests discussed above were performed with the standard displacer provided by the manufacturer with the ATG gauge. However, it is Teflon coated, which cannot withstand the radiation environment. A special stainless steel displacer was fabricated and tested. It has a $50.8 \mathrm{~mm}$ (2 in) 0.0., 20.3 $\mathrm{cm}^{2}\left(3.15 \mathrm{in}^{2}\right)$ surface area, $27.3 \mathrm{~cm}^{3}\left(1.66 \mathrm{in}^{3}\right)$ volume, and weighed approximately $223 \mathrm{gm}(0.49 \mathrm{lb})$. Note that this displacer weighed about the same as the displacer previously tested, but had only one-third the area and one-quarter of the volume of the other displacer. The results of the tests with this displacer indicated that the ATG gauge was able to determine the level of an air/liquid interface with a repeatability of \pm 0.01 in. (one standard deviation). This is consistent with the tests described above. However, because the volume of the displacer was smaller, the buoyant force on the displacer was only $2.8 \mathrm{gm}(0.006 \mathrm{lb}$.) different in the oil compared to water (the resolution of the ATG gauge is $\pm 3 \mathrm{gm}$ or $0.0066 \mathrm{lb}$.). As a result, the ATG gauge had difficulty determining the level of the oil/water interface. It was able to determine the water/molasses interface because of the larger change in density. 
The equation which describes the relationship between buoyant force and volume is given by:

$$
\Delta F=V\left(p_{a}-p_{b}\right)
$$

where $\Delta F=$ difference between buoyant forces as the displacer moves between two liquids, $a$ and $b$

$V=$ volume of displacer

$\rho_{\mathrm{a}}=$ density of liquid a

$P_{b}=$ density of liquid $b$

Thus, the difference between the buoyant forces as the displacer moves between two liquids decreases as the volume of the displacer decreases and as the two liquids approach the same density.

\section{STANLEY TOOL LASER MEASURING DEVICE}

Summary

A demonstration of the Stanley Tool Laser Measuring device was held at PNL on November 11, 1992. The device is expected to be marketed in March 1993. It uses visible red light, at a $670 \mathrm{~nm}$ wavelength, and an optical phase technique to determine the distance to a target. The spot was elliptical in shape, approximately $0.25 \times 0.5 \mathrm{in}$. at $28 \mathrm{ft}$. The basic test set-up is shown in Figure 18a. The optical beam from the device was propagated horizontally through a 3.75-in. I.D. gray plastic pipe approximately 19 feet long. The targets were mounted on an optical bench, and the distance between the nominal target surface and the back of the laser measuring device was measured using a steel measuring tape. The device measured the distance to the target in units of feet with a display containing three decimal digits. The precision of the device was demonstrated using several different targets, and the results of the tests are discussed below. The measured distance in the tables is an average value taken from a series of approximately five measurements without moving the measuring device or the target. The calculated values of one standard deviation from these measurements is also given in these tables. 


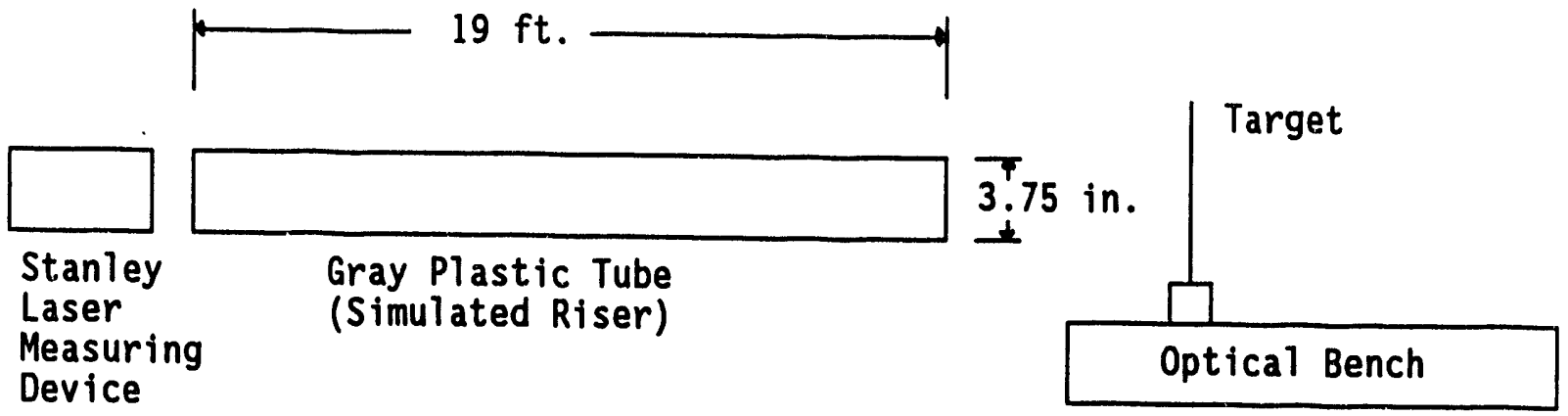

FIGURE 18a. Basic Test Set-Up

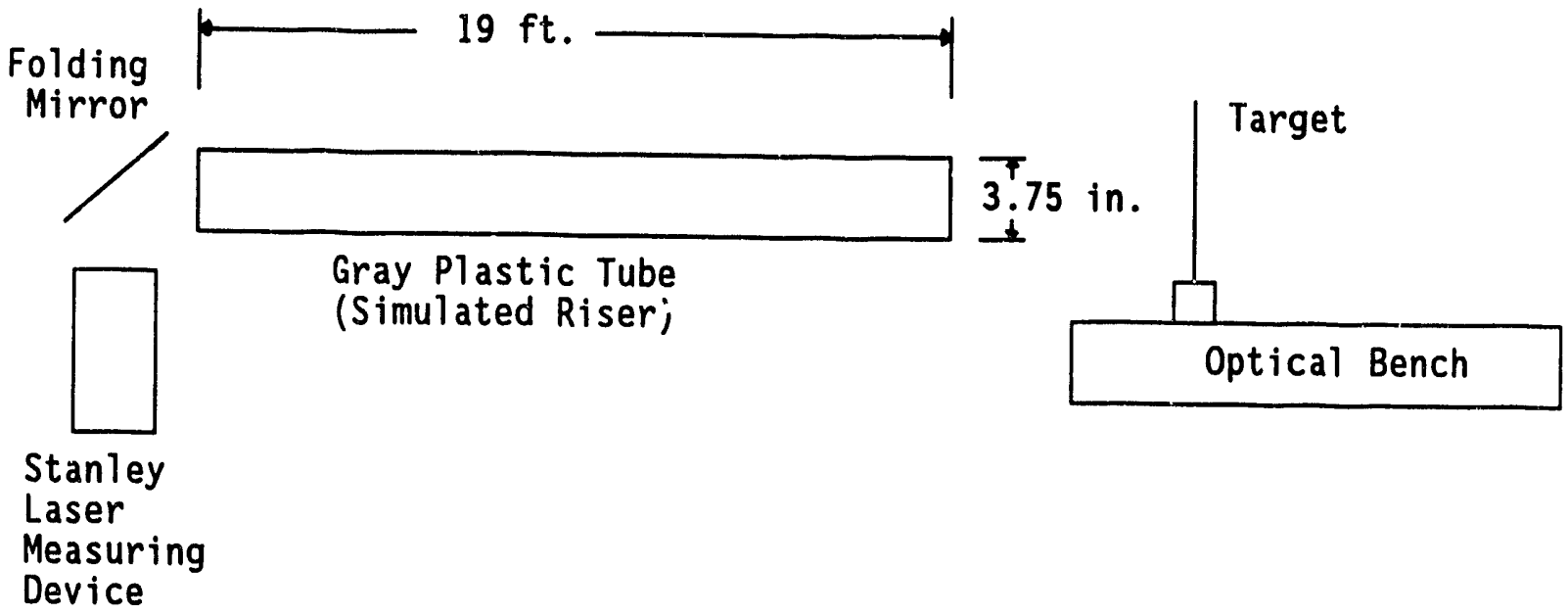

FIGURE 18b. Test Set-Up with Folding Mirror

FIGURE 18. Experimental Test Set-Up of Laser Measuring Device 


\section{Precision of the Stanley Tool Laser Measuring Device}

The precision of the Stanley Tool Laser Measuring device was tested against a simulated waste tank material with a rough surface (approximately 0.25 in. cavities in the surface). The simulated waste material was tan color. The results of the test are summarized in Table 6 . The projected beam was not always centered on the target. When this occurred, the distance to the target changed when the target was rotated to $45^{\circ}$.

The device had approximately the same precision at $45^{\circ}$ as it had when the target surface was normal to the path of the optical beam $(00)$. This occurred because the roughness of the target scattered light randomly in all directions. The value of the standard deviation in the distance measured by the device increased as the distance to the target increased. This would be expected because the magnitude of the signal from the target reaching the detector would decrease as the distance to the target increased. The Stanley Tool representative stated that the device that was tested in the demonstration used a $2.5 \mathrm{mw}$ laser diode, and they expect that the production model would have a $5 \mathrm{mw}$ laser diode. In addition, the prototype demonstration system included optical filters that were going to be revised in the production model. If the surface under the projected spot from the device exceeds $5 \mathrm{~mm}$. in depth, an error message was displayed in the output of the device. This occurred frequently with the rough target, especially when it was set at a $45^{\circ}$ angle. The measurement was retaken when this occurred.

TABLE 6. Precision of Laser Measuring Device Using Simulated Waste Tank Target

\begin{tabular}{l|c|c|c|c|c|c}
$\begin{array}{c}\text { True } \\
\text { Distance } \\
\text { (ft.) }\end{array}$ & $\begin{array}{l}\text { Average } \\
\text { Measured } \\
\text { Distance } \\
\text { (ft.) }\end{array}$ & \multicolumn{2}{|c|}{$\begin{array}{c}\text { Standard } \\
\text { Deviation } \\
\text { (ft.) }\end{array}$} & \multicolumn{2}{c}{$\begin{array}{c}\text { Average } \\
\text { Measured } \\
\text { Distance } \\
\text { (in.) }\end{array}$} & \multicolumn{2}{|c}{$\begin{array}{c}\text { Standard } \\
\text { Deviation } \\
\text { (ft.) }\end{array}$} & (ft.) & (in.) \\
\hline 28.125 & 27.982 & \pm 0.011 & \pm 0.132 & 27.962 & \pm 0.010 & \pm 0.120 \\
35.333 & 35.156 & \pm 0.034 & \pm 0.410 & 35.192 & \pm 0.037 & \pm 0.444 \\
48.458 & 48.491 & \pm 0.057 & \pm 0.684 & 48.491 & \pm 0.025 & \pm 0.300
\end{tabular}


Precision of Device Using a Folding Mirror

In actual use, because the Stanley Optical Measuring device is not radiation hardened, a mirror would be placed at the input end of the riser to prevent direct radiation shine from reaching the device, as shown in Figure 18b. This set-up was tested using the simulated waste tank target, and the results are shown in Table 7 . Due to the low power of the device and the loss in the signal strength due to the reflection from the first surface aluminized mirror, it was not able to detect the rough target at 43 feet. The value of the standard deviation in the measured distance at 28 feet is slightly larger than it was without the mirror, again due to the decrease in the received signal strength.

\section{Smooth Target Versus Rough Target}

A smooth white diffusing target was substituted for the rough simulated waste target. The folding mirror was used for this test. With the target positioned perpendicular to the optical beam path, the distance measured by the device for the rough target was $28.901 \mathrm{ft}$. with a standard deviation of $\pm 0.026 \mathrm{ft} .( \pm 0.312 \mathrm{in.})$; and for the smooth target, the distance to the target was measured to be $28.882 \mathrm{ft}$. with a standard deviation of $\pm 0.019 \mathrm{ft}$. $( \pm 0.230 \mathrm{in.})$. Thus, an increase in the value of the standard deviation is noted in using a rough target compared to a smooth target, again due to the decrease in the received signal strength from the rough target.

Accuracy of the Device

A test was conducted to determine the ability of the device to measure changes in the distance to the target. The results are summarized in Table 8

TABLE 7. Precision of Laser Measuring Device Using Simulated Waste Tank Target and a Folding Mirror

\begin{tabular}{|c|c|c|c|c|c|c|}
\hline \multirow[b]{2}{*}{$\begin{array}{l}\text { True } \\
\text { Distance } \\
\text { (ft.) }\end{array}$} & \multicolumn{3}{|c|}{$0^{\circ}$} & \multicolumn{3}{|c|}{$45^{\circ}$} \\
\hline & $\begin{array}{c}\text { Average } \\
\text { Measured } \\
\text { Distance } \\
(\text { ft.) }\end{array}$ & $\begin{array}{r}\text { Stan } \\
\text { Devi } \\
\text { (ft.) }\end{array}$ & $\begin{array}{l}\text { ard } \\
\text { tion } \\
\text { (in.) }\end{array}$ & $\begin{array}{c}\text { Average } \\
\text { Measured } \\
\text { Distance } \\
\text { (ft.) }\end{array}$ & $\begin{array}{l}\text { Stand } \\
\text { Devia } \\
\text { (ft.) }\end{array}$ & $\begin{array}{l}\text { rd } \\
\text { ion } \\
\text { (in.) }\end{array}$ \\
\hline $\begin{array}{l}28.750 \\
42.938\end{array}$ & 28.226 & \pm 0.013 & $t^{0} 0.156$ & $\begin{array}{l}28.236 \\
\text { ct Target }\end{array}$ & \pm 0.021 & \pm 0.252 \\
\hline
\end{tabular}


for the rough simulated waste tank material and Table 9 for the smooth white target. Again, the results indicate a slightly better accuracy using the smooth white target than the simulant due to the increase in received signal strength from the smooth target.

\section{Effect of Device Warm-Up}

The distance measured by the device was compared before and after it was allowed to warm up for a few minutes. At a distance of $27.708 \mathrm{ft}$., the distance to the white diffusing target was measured to be $27.596 \mathrm{ft}$. With a standard deviation of $\pm 0.030 \mathrm{ft} .( \pm 0.360 \mathrm{in.})$ before the device warmed up, and the distance was measured to be $27.592 \mathrm{ft}$. with a standard deviation of $\pm 0.014 \mathrm{ft}$. ( $\pm 0.168 \mathrm{in.})$ after the device warmed up. Thus, a decrease in the value of the standard deviation was noted after the device warmed up.

TABLE 8. Accuracy of Laser Measuring Device Using Simulated Waste Tank Target and a Folding Mirror

\begin{tabular}{|c|c|c|c|c|c|}
\hline $\begin{array}{c}\text { True } \\
\text { Distance } \\
\text { (ft.) }\end{array}$ & $\begin{array}{l}\text { Change in } \\
\text { Distance } \\
\text { (in.) }\end{array}$ & $\begin{array}{l}\text { Measured } \\
\text { Distance } \\
(\text { ft.) }\end{array}$ & $\begin{array}{c}\text { Standarc } \\
\text { (ft.) }\end{array}$ & eviation & $\begin{array}{c}\text { Measured Change } \\
\text { in Distance } \\
\text { (in.) }\end{array}$ \\
\hline $\begin{array}{l}20.875 \\
20.896 \\
20.917\end{array}$ & $\begin{array}{l}\text { Base } \\
0.25 \\
0.50\end{array}$ & $\begin{array}{l}20.854 \\
20.873 \\
20.910\end{array}$ & $\begin{array}{l} \pm 0.015 \\
\pm 0.009 \\
\pm 0.024\end{array}$ & $\begin{array}{l} \pm 0.180 \\
\pm 0.180 \\
\pm 0.288\end{array}$ & $\begin{array}{l}\text { Base } \\
0.228 \\
0.672\end{array}$ \\
\hline
\end{tabular}

TABLE 9. Accuracy of Laser Measuring Device Using a White Diffuse Target and a Folding Mirror

\begin{tabular}{|c|c|c|c|c|c|}
\hline $\begin{array}{c}\text { True } \\
\text { Distance } \\
\text { (ft.) }\end{array}$ & $\begin{array}{l}\text { Change in } \\
\text { Distance } \\
\text { (in.) }\end{array}$ & $\begin{array}{l}\text { Measured } \\
\text { Distance } \\
(\text { ft.) }\end{array}$ & $\begin{array}{c}\text { Standard } \\
\text { (ft.) }\end{array}$ & Deviation & $\begin{array}{c}\text { Measured Change } \\
\text { in Distance } \\
\text { (in.) }\end{array}$ \\
\hline $\begin{array}{l}27.708 \\
27.750 \\
27.791 \\
28.041 \\
28.791\end{array}$ & $\begin{array}{r}\text { Base } \\
0.50 \\
1.00 \\
4.00 \\
13.00\end{array}$ & $\begin{array}{l}27.592 \\
27.640 \\
27.662 \\
27.911 \\
28.863\end{array}$ & $\begin{array}{l} \pm 0.014 \\
\pm 0.012 \\
\pm 0.008 \\
\pm 0.018 \\
\pm 0.015\end{array}$ & $\begin{array}{l} \pm 0.168 \\
\pm 0.144 \\
\pm 0.096 \\
\pm 0.216 \\
\pm 0.180\end{array}$ & $\begin{array}{c}\text { Base } \\
0.576 \\
0.840 \\
3.828 \\
15.252\end{array}$ \\
\hline
\end{tabular}




\section{Other Targets}

The device was not able to detect clear water in a beaker at approximately $21.4 \mathrm{ft}$. It was able to detect the bottom of a dry beaker at $21.4 \mathrm{ft}$. It was not able to detect the distance to a black piece of paper at $21.4 \mathrm{ft}$. nor a dark brown case at $28.9 \mathrm{ft}$. The device was able to detect the distance to a specular (mirror) surface, but an error message was displayed because too much light was reaching the receiver.

\section{Effect of Room Lights}

The distance measured by the device was not degraded at $48.5 \mathrm{ft}$. by having fluorescent laboratory room lights on in comparison to having the lights off.

\section{ROBERTSHAW 185A INVEN-TELه PRECISION LEVEL GAUGE}

\section{Summary}

The Model 185A Inven-Te10 Precision Level Gauge produced by Robertshaw was tested to determine its precision to measure the distance to the surface of the material in the waste tanks. A stainless steel tape, approximately 0.5 in. wide, is attached to a probe that is lowered to the surface to be measured. When the probe contacts the surface, an electric circuit is completed (the other part of the circuit is taken from the wall of the tank), and the distance to the surface is measured by reading an encoder on the motor controlling the lowering of the tape. The system is intrinsically safe and explosion-proof for certain hazardous locations, but these do not include a location with hydrogen gas.

The accuracy and precision of the device is a function of the amount of electrical resistance in the waste tank contents. It was determined that there was no measurable error in the precision of the device as long as the resistance of the waste contents was below $300 \mathrm{~m}$. The amount of error in the repeatability of the measurement to the surface level increased as the resistance increased between 300 to $400 \mathrm{M}$. After $400 \mathrm{M}$, the device could not detect the surface leve1. It was determined that the simulated waste tank materials exhibit approximately $1 \mathrm{M}$ resistance when the two probes used to measure the resistance were separated by one inch. The distance to the 
surface could not be determined using the slack switch on the Robertshaw gauge. Thus, it would not be able to determine the level to a nonconducting surface.

\section{Test Set-Up}

The Robertshaw gauge was set-up as shown in Figure 19. The probe is 6 in. long and has a $1 \mathrm{in}$. diameter. The stainless steel tape is $0.5 \mathrm{in}$. wide and $0.004 \mathrm{in}$. thick. The tank was a stainless steel beaker, 3.5 in. I.D. and $4.75 \mathrm{in.} \mathrm{high.} \mathrm{The} \mathrm{electrical} \mathrm{connection} \mathrm{was} \mathrm{made} \mathrm{from} \mathrm{the} \mathrm{Robertshaw} \mathrm{probe}$ tc - return path that goes through the water in the tank and the stainless steel beaker to a grounding strap connected to an aluminum contact plate, which was connected through a resistance box back to the Robertshaw gauge. Repeatability

The repeatability of the gauge was tested two different ways. In the first mode, the gauge was ailowed to automatically cycle every five seconds to determine the water level. The distance to the surface measured to $0.01 \mathrm{in}$. did rot vary over sixteen measurements. In the second mode, the probe was manualis raised and then lowered to determine the water level. Only two out of sixteen measurements varied by $0.01 \mathrm{in}$. Both of these tests indicate that the repeatability of the Robertshaw gauge falls within the resolution of the instrument, which is $\pm 0.01 \mathrm{in}$.

\section{Accuracy}

The accuracy of the device was tested by removing and adding water to the tank. The Robertshaw yauge tracked the 1.47-in. change in the water level with no error (measured to 0.01 in.).

\section{Slack Switch}

The FIC gauge has a slack switch on the tape so that if the probe reaches a hard nonconducting surface, the tape goes slack and the level can still be measured (although maybe less accurately). Altnuugh the Robertshaw gauge did detect when the tape became slack, the display on the gauge read an error signal, and no distance to the surface was displayed. An "error 2" was displayed on the output display if the slack occurred in a smooth motion, and this was easily recoverable by manually raising the probe. An "error 1" was 


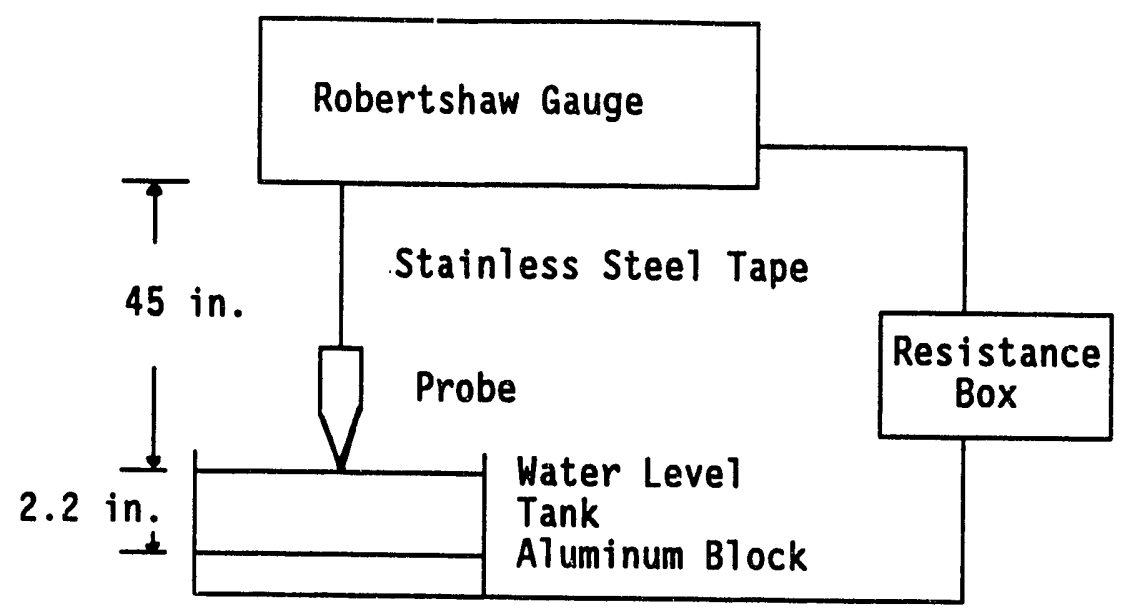

FIGURE 19. Experimental Test Set-up of Robertshaw Gauge

displayed on the output if a jerk occurred as the tape became slack. In order to recover from this error, it was necessary to bring the probe up to its home position.

\section{Resistance}

All of the above tests were done with a relatively low resistance return path. When the electrical contact was made, the probe barely touched the water surface. A resistance box was used to increase the resistance in the return path, as would occur if the waste tank contents became drier or a greater distance occurred between the probe and the wall of the tank. It was determined that as long as the resistance of the return path remained below approximately $300 \mathrm{M} \Omega$, the Robertshaw gauge exhibited the high degree of repeatability and accuracy that was discussed previously. From 300 to $400 \mathrm{Mr}$, the gauge became less accurate and less repeatable, as shown in Table 10. The accuracy of the gauge was affected because in order to register contact, more of the gauge was submerged in the water. At $400 \mathrm{Mn}$ or greater, the gauge was not able to detect the surface level. The error stated in Table 10 is the value of one standard deviation. WHC has indicated that a similar test was conducted on the FIC gauge many years ago and that the maximum resistance that could be in the feedback loop of the FIC gauge was $250 \mathrm{k} \Omega$. Thus, the 
TABLE 10. Effect of Adding Resistance on Accuracy and Precision of the Robertshaw Gauge

\begin{tabular}{c|c|c}
$\begin{array}{c}\text { Resistance } \\
\text { (MR) }\end{array}$ & $\begin{array}{c}\text { Change in Leve1 } \\
\text { Measurement } \\
\text { (in.) }\end{array}$ & $\begin{array}{c}\text { Error in Leve1 } \\
\text { Measurement } \\
\text { (in.) }\end{array}$ \\
\hline 300 & Base & \pm 0.01 \\
310 & 0.00 & \pm 0.02 \\
350 & 0.29 & \pm 0.03 \\
370 & 1.04 & \pm 0.04 \\
390 & 2.81 & \pm 0.04
\end{tabular}

Robertshaw gauge may be able to determine the level of some surfaces that the present FIC gauge cannot determine.

To determine the importance of the resistance of the return path, the amount of resistance through various fluids was measured using a two-point contact probe. When the two contact points were one inch apart, a liquid waste tank simulant exhibited 0.5 to $2 \mathrm{M}$ resistance, depending on the surface. In comparison, the resistance of tap water was measured to be 0.8 $\mathrm{M} \Omega$, and salt water was $0.2 \mathrm{Mn}$.

\section{MICRO SWITCH 942 ACOUSTIC SENSOR}

\section{Summary}

A quick test was performed to determine the ability of the MICRO SWITCH acoustic sensor to detect level changes on simulated waste tank material. When the acoustic sensor was originally tested in $1991^{(a)}$, the accuracy of the sensor was never tested against simulated waste tank material.

\section{Test Results}

For this test, the distance from the sensor to the targets ranged from approximately 44 to $48 \mathrm{in}$. The distance to the targets was incremented randomly, with increments ranging from 0.25 to 2.5 in. Three targets were used: dry sinulated waste, wet simulated waste, and water. We used the

(a) Spanner, J. C., Peters, T. J., Park, W. R., and Lechelt, W. M., September 1991. "Evaluation of Acoustic Sensors for Single-Shell Storage Tanks: Laboratory Test Phase," pp. 11-28, draft report delivered to R. Welty of Westinghouse Hanford Company. 
equation we generated in the tests in 1991 to convert the voltage output of the sensor to a distance measurement.

The results of the tests are summarized in Tables 11 through 13 . The average error in measuring an increment with:

- the dry simulated waste was 0.023 in.

- the wet simulated waste was 0.045 in.

- the water was 0.038 in.

The voltage output from the acoustic sensor did fluctuate occasionally during the test, probably due to the fact that the diameter of the simulated waste material was only $4 \mathrm{in}$. whereas the diameter of the spot at $48 \mathrm{in}$. is $16.4 \mathrm{in.}$ The diameter of the container of water was $12 \mathrm{in.}$ When the voltage output from the sensor became unstable, testing was either discontinued until the sensor restabilized or the test was stopped.

TABLE 11. Accuracy of Sonic Sensor Using Dry Simulated Waste Material

\begin{tabular}{l|c|c|c|c|c}
$\begin{array}{c}\text { True } \\
\text { Distance } \\
\text { (in.) }\end{array}$ & $\begin{array}{c}\text { True } \\
\text { Increment } \\
\text { (in.) }\end{array}$ & $\begin{array}{c}\text { Measured } \\
\text { Distance } \\
\text { (in.) }\end{array}$ & $\begin{array}{c}\text { Measured } \\
\text { Increment } \\
\text { (in.) }\end{array}$ & $\begin{array}{c}\text { Error in } \\
\text { Increment } \\
\text { (in.) }\end{array}$ & \multicolumn{1}{|c}{ Notes } \\
\hline 48.000 & --- & 47.900 & --- & --- & Floor \\
47.000 &.-- & 47.400 &.-- &.-- & Simulated Waste on Floor \\
44.500 & 2.500 & 44.910 & 2.490 & 0.010 & \\
44.250 & 0.250 & 44.650 & 0.260 & 0.010 & \\
44.000 & 0.250 & 44.450 & 0.200 & 0.050 &
\end{tabular}

Average Error in Measuring Incremental Change $=0.023$ in.

TABLE 12. Accuracy of Sonic Sensor Using Wet Simulated Waste Material

\begin{tabular}{|c|c|c|c|c|c|}
\hline $\begin{array}{c}\text { True } \\
\text { Distance } \\
\text { (in.) }\end{array}$ & $\begin{array}{c}\text { True } \\
\text { Increment } \\
\text { (in.) }\end{array}$ & $\begin{array}{c}\text { Measured } \\
\text { Distance } \\
\text { (in.) }\end{array}$ & $\begin{array}{l}\text { Measured } \\
\text { Increment } \\
\text { (in.) }\end{array}$ & $\begin{array}{l}\text { Error in } \\
\text { Increment } \\
\text { (in.) }\end{array}$ & Notes \\
\hline $\begin{array}{l}47.750 \\
46.250 \\
44.000 \\
43.750 \\
43.375\end{array}$ & $\begin{array}{l}\cdots . . \\
\cdots \cdots \\
2.250 \\
0.250 \\
0.375\end{array}$ & $\begin{array}{l}47.803 \\
46.787 \\
44.552 \\
44.196 \\
43.840\end{array}$ & $\begin{array}{l}\cdots-. \\
\cdots-. \\
2.235 \\
0.356 \\
0.356\end{array}$ & $\begin{array}{l}\cdots . . \\
0.010 \\
0.106 \\
0.019\end{array}$ & $\begin{array}{l}\text { Floor } \\
\text { Simulated Waste on }\end{array}$ \\
\hline
\end{tabular}

Average Error in Measuring Incremental Change $=0.045 \mathrm{in}$. 
TABLE 13. Accuracy of Sonic Sensor Using a Water Target

\begin{tabular}{|c|c|c|c|c|c|}
\hline $\begin{array}{c}\text { True } \\
\text { Distance } \\
\text { (in.) }\end{array}$ & $\begin{array}{c}\text { True } \\
\text { Increment } \\
\text { (in.) }\end{array}$ & $\begin{array}{l}\text { Measured } \\
\text { Distance } \\
\text { (in.) }\end{array}$ & $\begin{array}{l}\text { Measured } \\
\text { Increment } \\
\text { (in.) }\end{array}$ & $\begin{array}{l}\text { Error in } \\
\text { Increment } \\
\text { (in.) }\end{array}$ & Notes \\
\hline $\begin{array}{l}48.000 \\
47.750 \\
46.875 \\
46.375 \\
46.125 \\
45.625 \\
45.375\end{array}$ & \begin{tabular}{l}
$\cdots-$ \\
\hdashline.-- \\
0.875 \\
0.500 \\
0.250 \\
0.500 \\
0.250
\end{tabular} & $\begin{array}{l}47.854 \\
46.701 \\
46.880 \\
46.380 \\
46.126 \\
45.669 \\
45.364\end{array}$ & $\begin{array}{l}\cdots . . \\
0.921 \\
0.500 \\
0.254 \\
0.557 \\
0.335\end{array}$ & $\begin{array}{l}\cdots \cdots \\
0.046 \\
0.000 \\
0.004 \\
0.057 \\
0.085\end{array}$ & $\begin{array}{l}\text { Floor } \\
\text { Dry Bucket on Floor } \\
\text { Add Water to Bucket }\end{array}$ \\
\hline
\end{tabular}




\section{OTHER TECHNIQUES}

Several other products were reviewed in the course of this project. The results of this product search are discussed below. These are suppliers that were contacted as part of this study. All possible vendors may not be listed. The data is presented for information only.

\section{ELECTRO-OPTICAL RANGEFINDERS}

Electro-optic rangefinders, similar to the Stanley measuring device, are available on the market. Generally they operate by pulsing an infrared (invisible) light-emitting diode. Usually they are low-power, eye-safe devices. WHC contacted Savannah River who is presently testing the model DIOR 3002 Leica Distomatm infrared surveying instrument on a liquid surface. Generally, the best accuracy that can be obtained from these instruments without the use of reflectors on the target is 0.2 to $0.4 \mathrm{in}$., and it may be worse on an uneven, dark surface. Commercial systems are not intrinsically safe or radiation hardened.

\section{BUBBLERS}

Bubbler systems measure the surface level by measuring the pressure in a air line that is connected to a tube placed within the liquid to be measured. The end of the tute that is in the liquid contains a restricted opening, and the air pressure applied to the tube is adjusted so that a stream of bubbles is generated at the opening. The pressure at the top of the line corresponds to the flow rate of the air, the liquid level, and its density. By employing two devices separated at different levels in the liquid, the density of the fluid can be determined. The advantage of this technique is that only the tube needs to be immersed in the fluid. The measurement apparatus, e.g., pressure gauges, can be located at the top of the waste tank. But the method is susceptible to leaks and clogging of the opening of the tube. Thus, it would have to be used in liquid surfaces that do not contain a large amount of suspended particles. It could not be placed in a waste tank that exhibits surface motion because the tube could become bent. 
WHC and PNL personnel talked with representatives of Omega Environmental, Inc., who have developed a proprietary bubbler technique that presently measures the liquid level with an accuracy of $0.1 \mathrm{in.}$, and they claim the device could achieve an accuracy of 0.02 in. or better. Because patents are presently being pursued on the device, they were not very explicit on how the device operates. They would need development funds to determine how accurately their device could be used in the liquid waste tank environment.

A level detection system that uses a modified bubbler technique is produced by Moore Instruments. A 3.5-in. diameter level transmitter is attached to a 0.125 -in. air line that maintains constant air flow. The pressure is monitored using a T-fitting at the top of the tank so the pressure at the fitting equals the pressure at the diaphragm. Unlike normal bubbler systems, the air is not released into the liquid, thus eliminating clogging of the restricted opening or contamination of the material. This device has a $\pm 0.25 \mathrm{in}$. accuracy in depths of 2 to $100 \mathrm{in}$. of water. A 2.25-in. diameter model has a $\pm 0.50 \mathrm{in}$. accuracy in depths of 2 to $100 \mathrm{in}$. of water. The device is made of 316 stainless steel, which should take the caustic and radiation environment, and can operate up to $350^{\circ} \mathrm{F}$. However, the standard diaphragm is Teflon-coated fiberglass, which will not take the radiation.

\section{OTHER RADAR GAUGES}

WHC and PNL personnel talked with Krohne America, Inc., regarding their BM 70 Level-Radar Gage. It operates on the same principle as the Enraf radar gauge discussed previously. The advantage of this gauge is that it is small enough to fit down a riser; thus, it could be placed within a few feet of the surface. Its accuracy is better than $\pm 0.5 \%$ of the measured range and has a resolution of \pm 0.04 in. It is intrinsically safe, but its radiation tolerance is unknown. It has Teflon parts in the horn of the antenna. Because it operates at the same frequency and on the same principle as the Enraf radar gauge, it would be expected to exhibit the same problems of accurately determining the surface level when the characteristics of the surface change. It has approximately 20 set-up parameters that can be easily changed which will allow this radar gauge to be tailored to a particular configuration. One 
of these parameters may allow the radar gauge to ignore the signal from a salt cake that floats in the field of view.

\section{PRESSURE TRANSDUCERS}

Pressure transducers operate on the principle that the pressure at the location of a sensor increases directly with the depth of the liquid above it. If two transducers are placed at different levels, the density of the liquid can be determined. Pressure transducers are relatively inexpensive devices. However, they must be immersed in the waste tank material, and thus need to operate in the extreme temperature ranges, radiation fields, and the potential explosive and caustic environments of the waste tank. In addition, they may drift over time and temperature and it would be difficult to recalibrate them after they are placed in the waste tank. Thus, they probably will not exhibit the accuracy of some of the other devices investigated in this project. Their accuracy depends on the sensing range of the pressure transducer.

Several commercial pressure transducers have been recently installed in a waste tank on a Velocity Density Temperature Tree (VDTT). However, they failed prematurely for various reasons, including not surviving the caustic environment. A survey of other commercial suppliers of pressure transducers that could be used in the waste tank environment was conducted in this program. The results are given in Appendix $B$.

Several requirements were considered in reviewing the pressure transducers listed in Appendix B. The accuracy of the device was important, but also its size (3.75-in. diameter or less). The transducer was to operate in, and the output should be compensated for, a temperature range of 65 to $150^{\circ} \mathrm{F}$. Because of the caustic environment (pH 13), the type of housing that was used on the pressure transducer was considered (316 stainless steel will withstand the caustic environment better than some other stainless steels, although Inconel or Hastelloy C276 were considered by some of the contacts as better for the diaphragm) and whether the transducer is completely sealed in the housing. Unless the electronics is radiation hardened, it will degrade in the radiation environment. Thus, it would be better if the electronics were 
located separately from the transmitter. This also would help make the device intrinsically safe, which was also considered.

The results of the survey indicate that there are many different transducers on the market that may be able to operate in the caustic waste tank environment and temperatures. Some of these devices are known to be radiation hardened and intrinsically safe, or explosion-proof. There are several manufacturers who will fabricate custom devices to specifically meet the unique waste tank requirements. The table in Appendix $B$ could be used as a starting point for further investigations into the use of pressure transducers for level measurements in the waste tanks. 


\section{CONCLUSIONS}

The results of this study indicate that no one system can meet the requirements of measuring the surface level in all of the waste tanks. The problems associated with the waste contents are too diverse. Some of the waste tanks have a liquid surface, others a solid crust; some of the waste tanks have high heat loads while other tanks have hydrogen build-up; some of the waste tanks have a smooth surface while other tanks have a extremely rough surface. Thus, it is not possible for one commercially available device to meet all of these requirements.

Table 14 summarizes for which surface a certain gauge can be used. A11 of the gauges will obtain inconsistent readings if the surface is uneven and in motion, e.g., salt islands move into the field of view of the instrument. The radar gauge is best for homogeneous surfaces, i.e., liquid surfaces or solid surfaces that do not exhibit horizontal motion. Systems are already developed that are intrinsically safe. The Robertshaw gauge operates on the same principles as the FIC gauge, and could only be used on conducting surfaces. The ATG gauge is an improvement over the present FIC gauge because electrical contact is not required for it to operate. Thus, it could be used on dry surfaces. In addition, the ATG gauge can measure the level of liquids that are beneath liquids of less density. It can be programmed to compensate for the weight of crystal growth on the displacer. The amount of error in measuring the distance to the surface with the ATG gauge due to the volume change of the added crystal growth depends on the density of the crystals relative to the surface material. Optical rangefinders are also noncontact devices that potentially could be used in the waste tank but need to be further developed. One advantage of the acoustic sensor over the radar gauge is that it should be less expensive. But it needs to be radiation hardened and intrinsically safe. Because it is less expensive, it would possible to place several of these devices in a waste tank to obtain a level measurement in more than one place. Although bubblers have been developed with the required accuracy for waste tank applications, they would need to be used in liquid tanks that do not contain a large amount of suspended particles. The system manufactured by Moore Instruments may overcome some of the problems 
associated with bubbler devices. Pressure transducers are available that possibly could be used in waste tank applications, but their accuracy is lower than some of the other devices investigated in this study. 


\section{TABLE 14. Comparison of Different Level Measurement Instruments}

\begin{tabular}{|c|c|c|c|c|c|c|c|}
\hline $\begin{array}{c}\text { Surface } \\
\text { Characteristics }\end{array}$ & Radar & AT6 & Sonic & $\begin{array}{c}\text { Optical } \\
\text { Rangefinder }\end{array}$ & $\begin{array}{l}\text { Robert- } \\
\text { shaw }\end{array}$ & Bubbler & $\mid \begin{array}{c}\text { Pressure } \\
\text { Transducer }\end{array}$ \\
\hline Clear Liquid & Yes & Yes & Yes & No (16) & Yes & Yes & Yes \\
\hline Unclear Liquid & Yes & Yes & Yes & Yes & Yes & (1) & Yes \\
\hline Soft (2) & (3) & Yes & Yes & Yes & (20) & No & Yes \\
\hline Hard (4) & (5) & (5) & (5) & (5) & (20) & No & Yes \\
\hline Dark & Yes & Yes & Yes & No & (20) & Yes & Yes \\
\hline $\begin{array}{l}\text { Salt Islands } \\
+ \text { Liquid (6) }\end{array}$ & Yes & Yes & Yes & Yes & (20) & $\begin{array}{l}\text { No } \\
\text { (7) }\end{array}$ & $\begin{array}{l}\text { No } \\
\text { (7) }\end{array}$ \\
\hline High Heat & Yes & (8) & (9) & (8) & Yes & (10) & Yes \\
\hline $\begin{array}{l}\text { Hydrogen } \\
\text { Generation }\end{array}$ & Yes & $\begin{array}{l}\text { Yes } \\
\text { (18) }\end{array}$ & (11) & $\begin{array}{l}\text { No } \\
\text { (12) }\end{array}$ & No & Yes & Yes \\
\hline $\begin{array}{l}\text { Accuracy (in.) } \\
(22)\end{array}$ & \pm 0.10 & \pm 0.01 & \pm 0.14 & \pm 0.02 & \pm 0.01 & \pm 0.10 & $\begin{array}{l} \pm 0.08- \\
\pm 2(19)\end{array}$ \\
\hline $\begin{array}{l}\text { Precision (in.) } \\
\text { (22) }\end{array}$ & \pm 0.05 & \pm 0.01 & \pm 0.02 & \pm 0.19 & \pm 0.01 & (21) & (21) \\
\hline Notes & (13) & (14) & (15) & (16) & (20) & (17) & (17) \\
\hline
\end{tabular}

MOTES:

1. Whether this technique works depends on the quantity of particles suspended in the 1 iquid.

2. Consistency similar to peanut butter.

3. Whether this technique works depends on the surface reflectivity.

4. Consistency similar to a snow cone.

5. Whether this technique works depends on the degree of unevenness of the surface.

6. All of the techniques will yield inconsistent results if the salt cake moves into the field of view of the instrument.

7. Cannot measure salt island. Surface movements could damage probe.

8. May be affected by thermal changes.

9. Cormercial systems that were tested only operated to $140^{\circ} \mathrm{F}$.

10. Depending on the design of the system.

11. Commercial systems are not intrinsically safe.

12. It would be necessary to keep the instrument out of the tank and project light through a window. Care would have to be taken to prevent the window from fogging up. Also, the riser needs to be straight.

13. To obtain accurate measurements requires that the surface not have appreciable changes in its conductivity or permittivity.

14. Salt crystals may grow on the displacer. a circumstance that will affect its accuracy depending on the density of the salt crystals compared to the surrounding liquid.

15. The sonic sensor did not have enough power, and had to be placed a few feet above the surface.

16. The device that was tested was not powerfui enough to accurately measure rough surfaces or a clear liquid. Other electro-optical rangefinders are avallable.

17. Needs to be placed in the waste materials, and hence must be able to withstand the radiation, heat, and highly caustic environment.

18. This device is certified to be explosion proof.

19. This assumes: 1) the full scale range of the pressure transducer is 1 psi. near the top of the tank and $25 \mathrm{psi}$. near the bottom of the tank: 2) the gage can be compensated for temperature effects. Long termI stability can double this error in one year of use.

20. Will detect surface level if the surface material conducts electric current.

21. These devices were not tested in this program.

22. Accuracy is the ability of the gauge to measure the distance to a target. Precision is the standard deviation of the gauge readings when the target position is not changing. 


\section{RECOMMENDATIONS}

Some of the devices investigated in this study should be placed in a waste tank. One device will not work for all of the waste tanks, therefore which device goes in a particular waste tank will depend on the characteristics of the contents. If it is necessary to measure the level of an interface below a less dense liquid with the ATG gauge, it may be necessary, depending on the change of density across the interface, to fabricate a displacer with a larger volume than the stainless steel displacer that was tested in this study. No coating was found in this study that minimized crystal growth on a probe that contacted the waste. The growth appears to occur when the probe is removed from the waste and allowed to dry above the contents. The probe should remain in the waste to minimize crystal growth. In addition, the probe should be periodically washed to remove crystal growth and obtain an accurate level measurement.

All of these devices measure only the distance to the surface at one place. Because the waste material is very inhomogeneous, it probably would be better to develop a device that will map the surface or measure it at several locations from one position. Even better would be a device that examines changes that are occurring below the surface, because surface changes may not reflect what is happening below the surface. A device that can detect changes inside the waste at various locations might be a more useful tool. Because of the high degree of attenuation in the waste material, this would not be a simple device to develop. The development of these concepts was beyond the scope of this project and needs to be examined further. 


\section{REFERENCES}

Peters, T. J., and Park, W. R., December 1992. Performance Evaluation of the Enraf-Nonius ${ }^{\mathrm{m}}$ Model 872 Radar Gauge. PNL-8464. Pacific Northwest Laboratory, Richland, Washington. 
APPENDIX A

CHEMICAL COMPONENTS IN WASTE TANK SIMULANT 


\section{APPENDIX A}

\section{CHEMICAL COMPONENTS IN WASTE TANK SIMULANT}

Component

$\mathrm{NaAlO}_{2}$

$\mathrm{Na}_{4}$ EDTA

$\mathrm{Na}_{3} \mathrm{HEDTA}$

$\mathrm{NaCl}$

$\mathrm{Na}_{3} \mathrm{PO}_{4}$

$\mathrm{NaNO}_{2}$

$\mathrm{NaNO}_{3}$

$\mathrm{Na}_{2} \mathrm{CO}_{3}$

NaF

$\mathrm{NaOH}$

$\mathrm{Cr}\left(\mathrm{NO}_{3}\right)_{3}$

$\mathrm{Cu}\left(\mathrm{NO}_{3}\right)_{2}$

$\mathrm{Fe}\left(\mathrm{NO}_{3}\right)_{3}$

$\mathrm{Ni}\left(\mathrm{NO}_{3}\right)_{2}$
Concentration

(In Molar Units)

2.1

0.17

0.35

0.35

0.20

3.1

3.1

0.4

0.1

2.7

$1.5 \times 10^{-3}$

$2.1 \times 10^{-4}$

$2.0 \times 10^{-3}$

$3.1 \times 10^{-3}$

\section{A. 1}


APPENDIX B

LIST OF COMMERCIALLY AVAILABLE PRESSURE TRANSDUCERS

NOTE: These are vendors contacted as part of this study. All possible vendors may not be on these lists. Items are listed alphabetically by manufacturer names. 


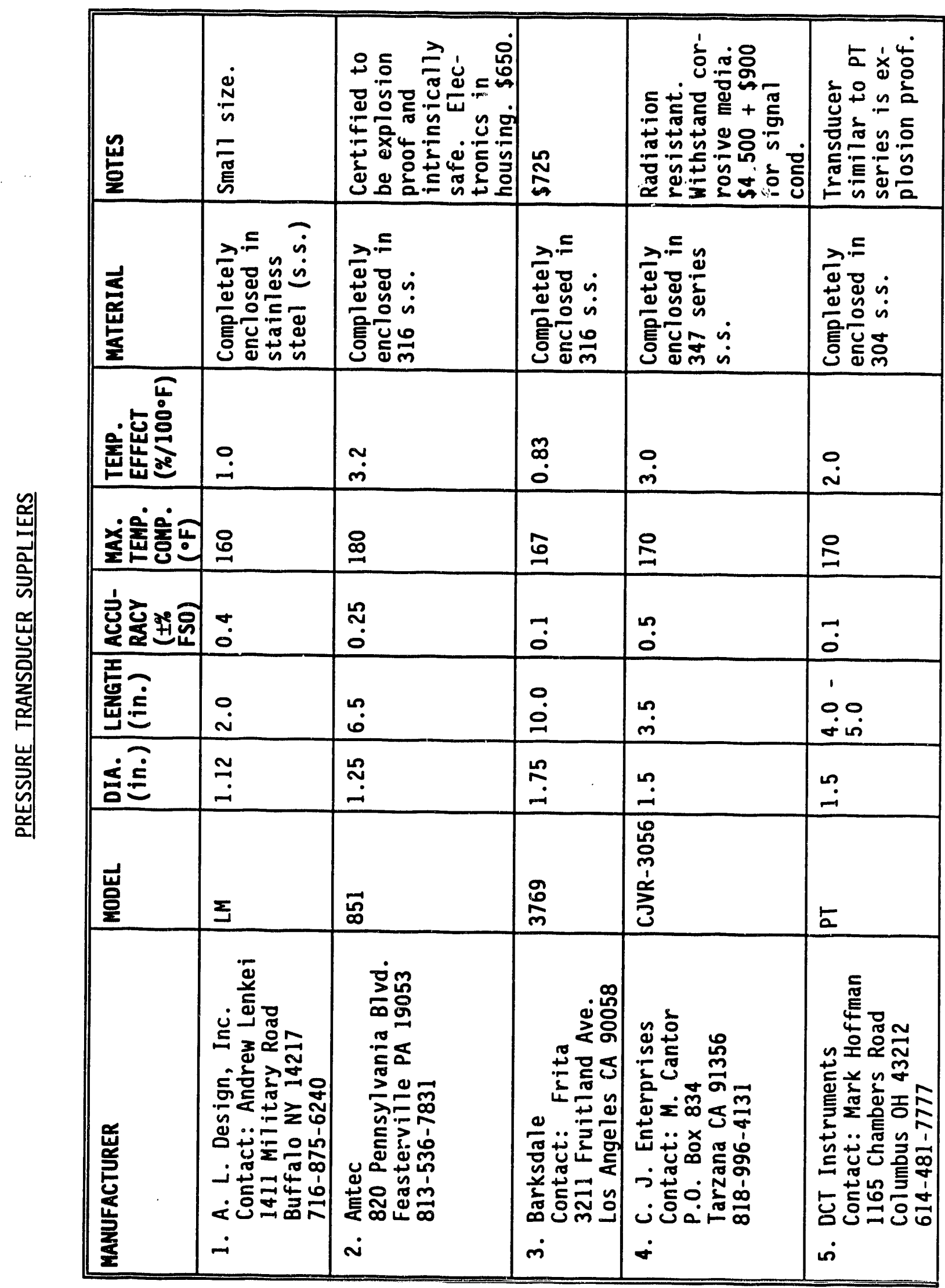

B. 1 


\begin{tabular}{|c|c|c|c|c|c|}
\hline 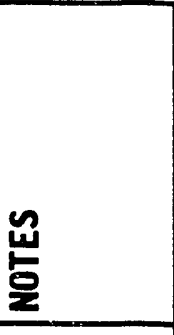 & 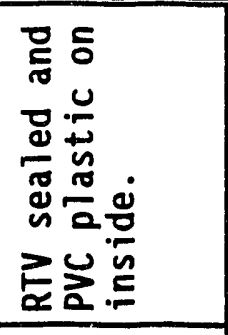 & 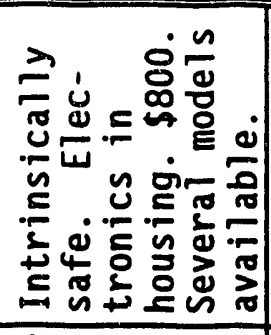 & 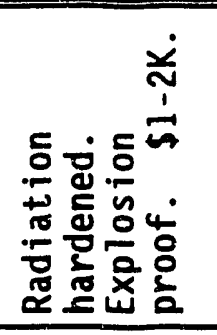 & 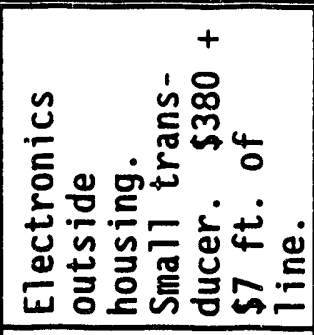 & 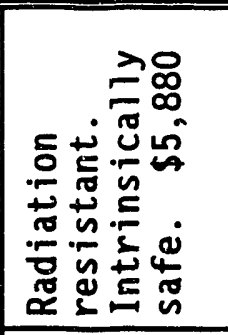 \\
\hline 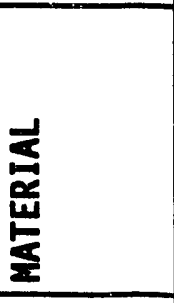 & 岁 & 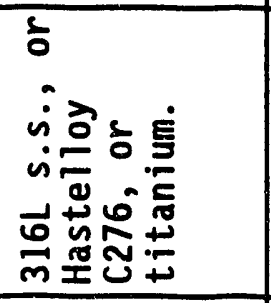 & 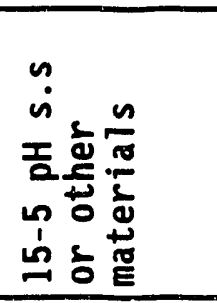 & $\begin{array}{l}\dot{\varphi} \\
\dot{s} \\
\dot{\tilde{c}}\end{array}$ & $\begin{array}{l}\dot{n} \\
\dot{n} \\
\dot{m} \\
\dot{m}\end{array}$ \\
\hline 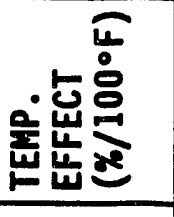 & $\begin{array}{l}\tilde{0} \\
\dot{0} \\
\end{array}$ & $\stackrel{\circ}{i} \stackrel{\circ}{i}$ & $\begin{array}{l}n \\
0 \\
0\end{array}$ & $\stackrel{i}{i}$ & $\begin{array}{l}\dot{d} \\
\stackrel{\dot{L}}{E} \\
\dot{o} \\
\dot{Q}\end{array}$ \\
\hline 逗产苟 & $\stackrel{ }{\simeq}$ & $\stackrel{\circ}{\Xi}$ & 品 & 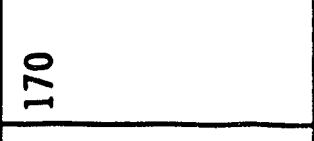 & $\tilde{్}$ \\
\hline 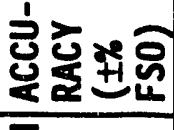 & $\begin{array}{l}\tilde{0} \\
0 \\
\end{array}$ & $\overrightarrow{0} \stackrel{0}{0}$ & 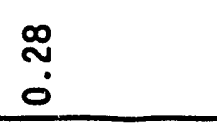 & $\stackrel{2}{\dddot{0}}$ & $\dddot{0}$ \\
\hline 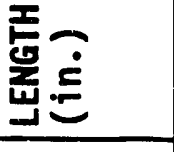 & $\stackrel{\circ}{\Gamma}$ & 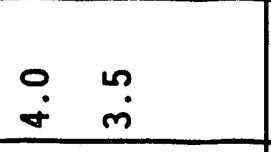 & $\stackrel{n}{m}$ & $\stackrel{n}{0}$ & 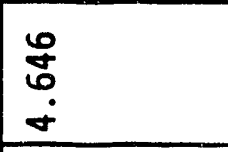 \\
\hline 可 & 吕 & 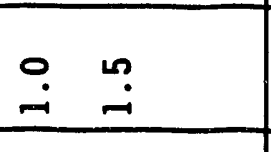 & $\stackrel{m}{i}$ & $\dot{0}$ & $\begin{array}{c}\tilde{\omega} \\
\dot{m} \\
\dot{m}\end{array}$ \\
\hline 뽛 & 品 & 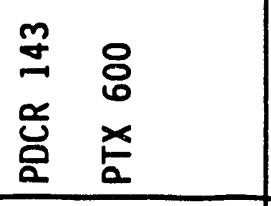 & 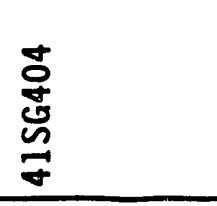 & ż & 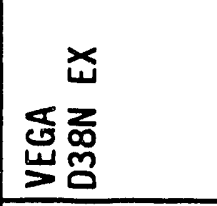 \\
\hline 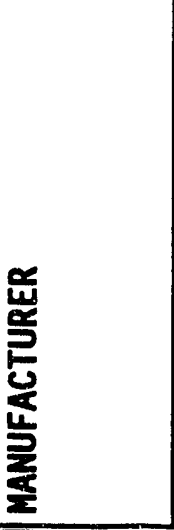 & 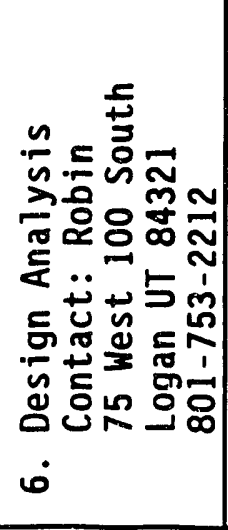 & 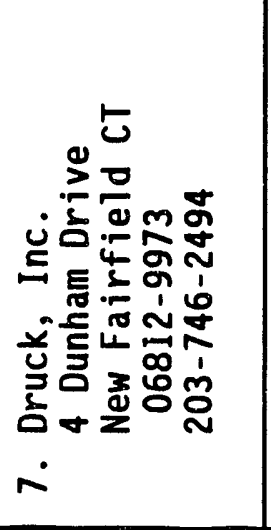 & 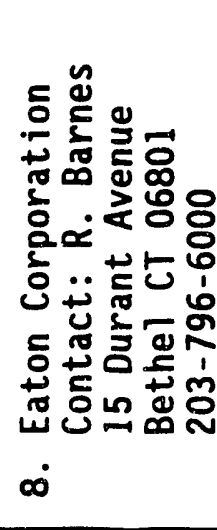 & 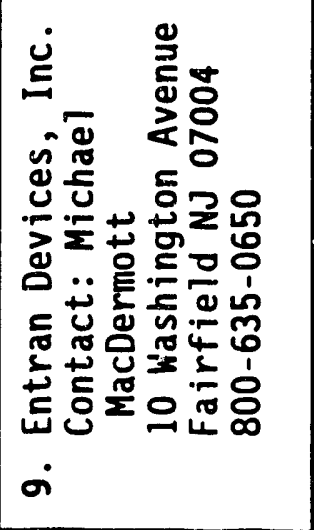 & 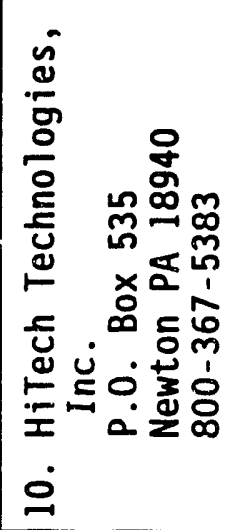 \\
\hline
\end{tabular}




\begin{tabular}{|c|c|c|c|c|}
\hline 쏭 & 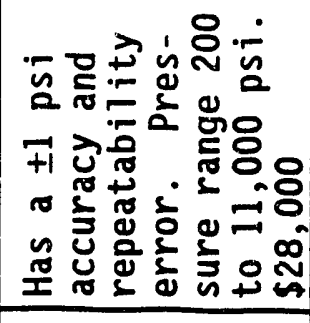 & 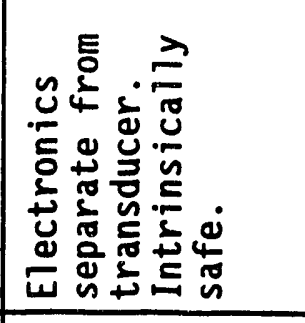 & 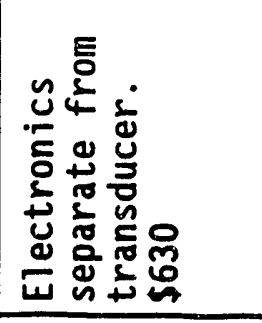 & 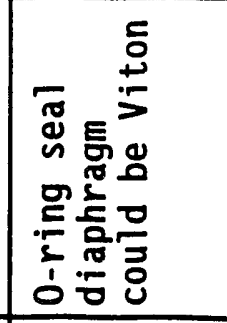 \\
\hline 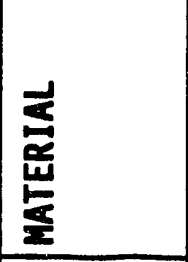 & 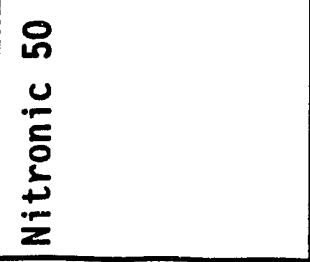 & 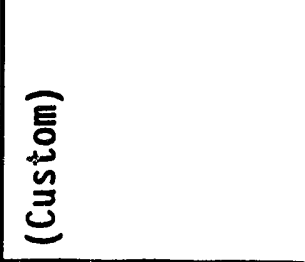 & 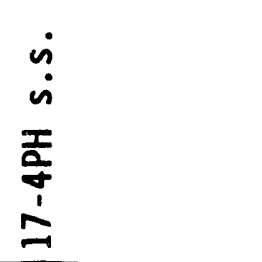 & 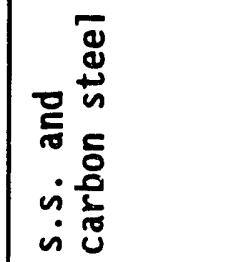 \\
\hline 遥豈点总 & $\begin{array}{r}\tilde{O} \\
\dot{0}\end{array}$ & $\ddot{0}$ & $\stackrel{20}{0}$ & $\because$ \\
\hline 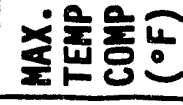 & 율 & ¿ & 吕 & 忍 \\
\hline 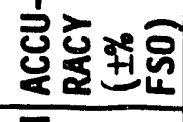 & $\begin{array}{l}0 \\
0 \\
\end{array}$ & $\ddot{0}$ & $\ddot{0}$ & $\ddot{0}$ \\
\hline 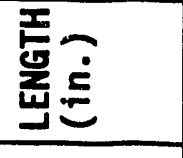 & $\stackrel{m}{\dot{m}}$ & & n'o & 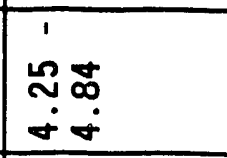 \\
\hline 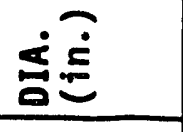 & $\stackrel{n}{=}$ & & $\stackrel{2}{-}$ & $\stackrel{\circ}{\circ}$ \\
\hline 폄 & $\stackrel{m}{\stackrel{m}{\sim}}$ & $\begin{array}{l}\tilde{E} \\
\stackrel{+}{ \pm} \\
\stackrel{n}{\Xi}\end{array}$ & 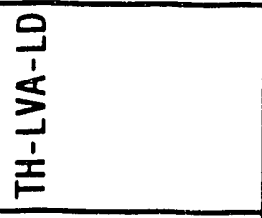 & 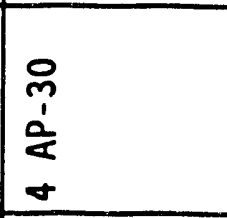 \\
\hline 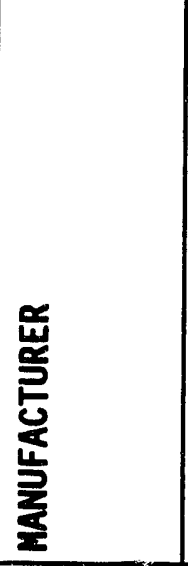 & 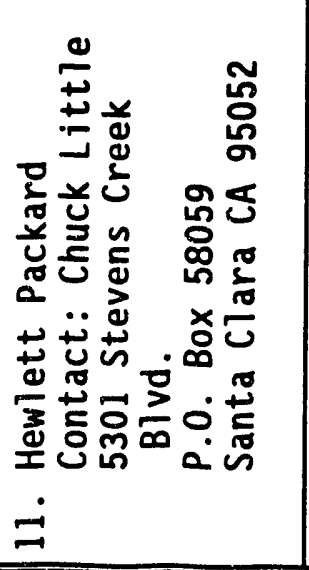 & 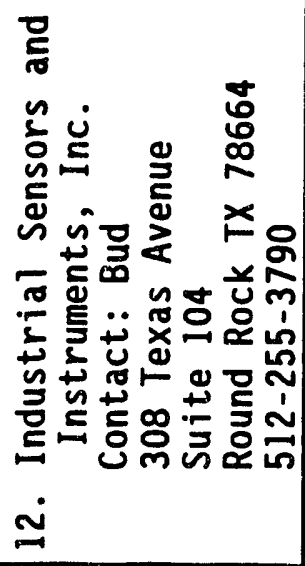 & 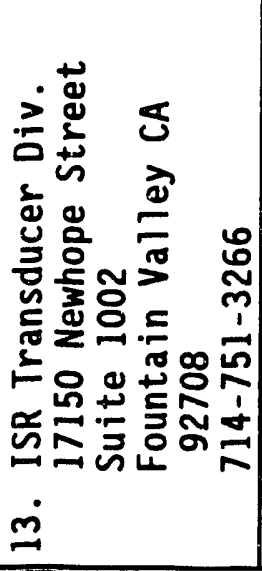 & 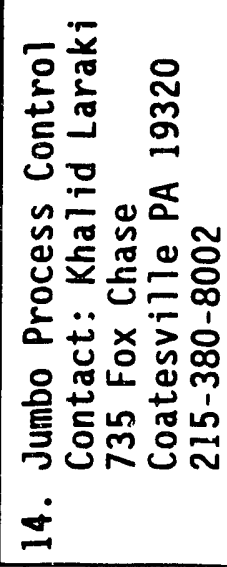 \\
\hline
\end{tabular}

B. 3 


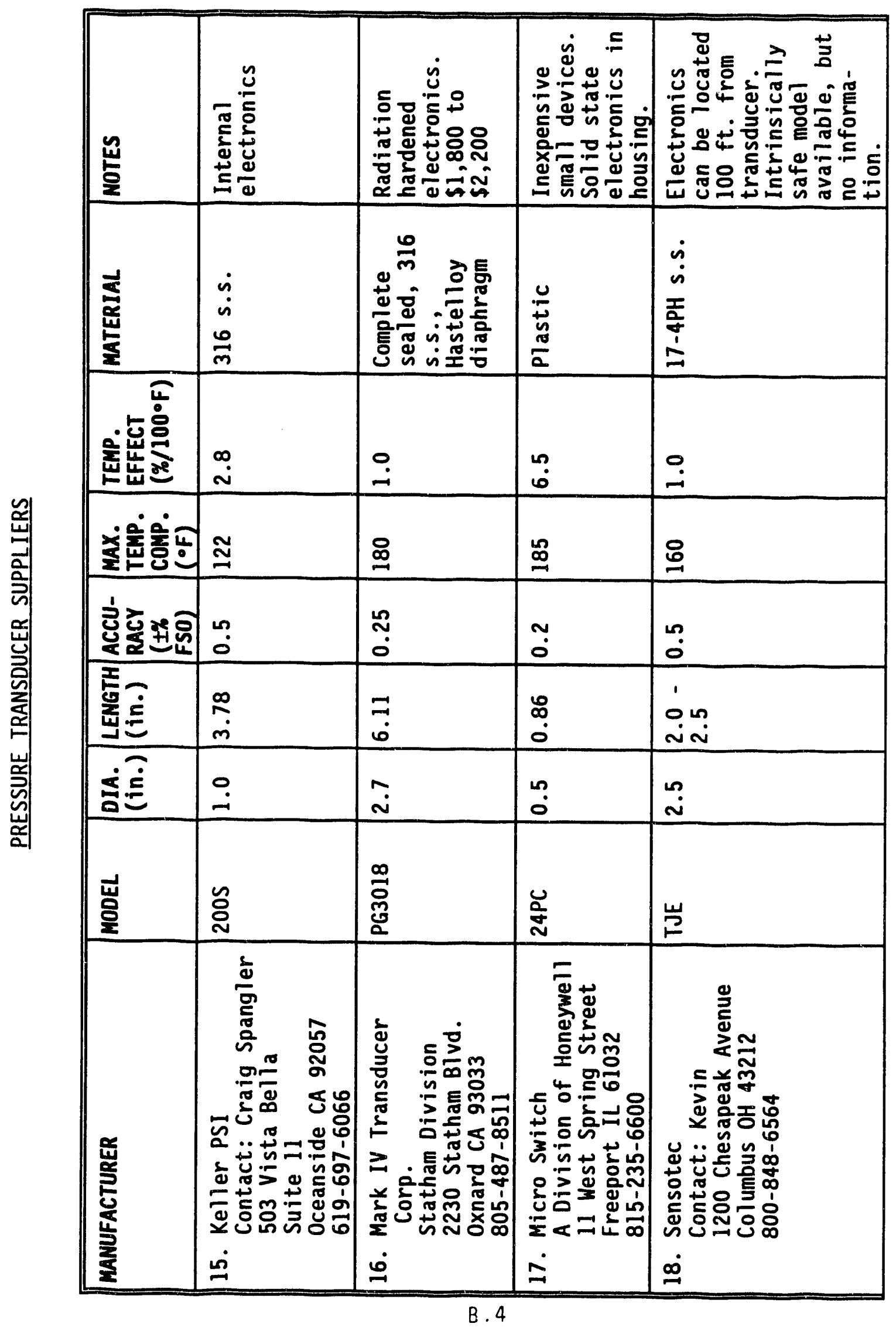




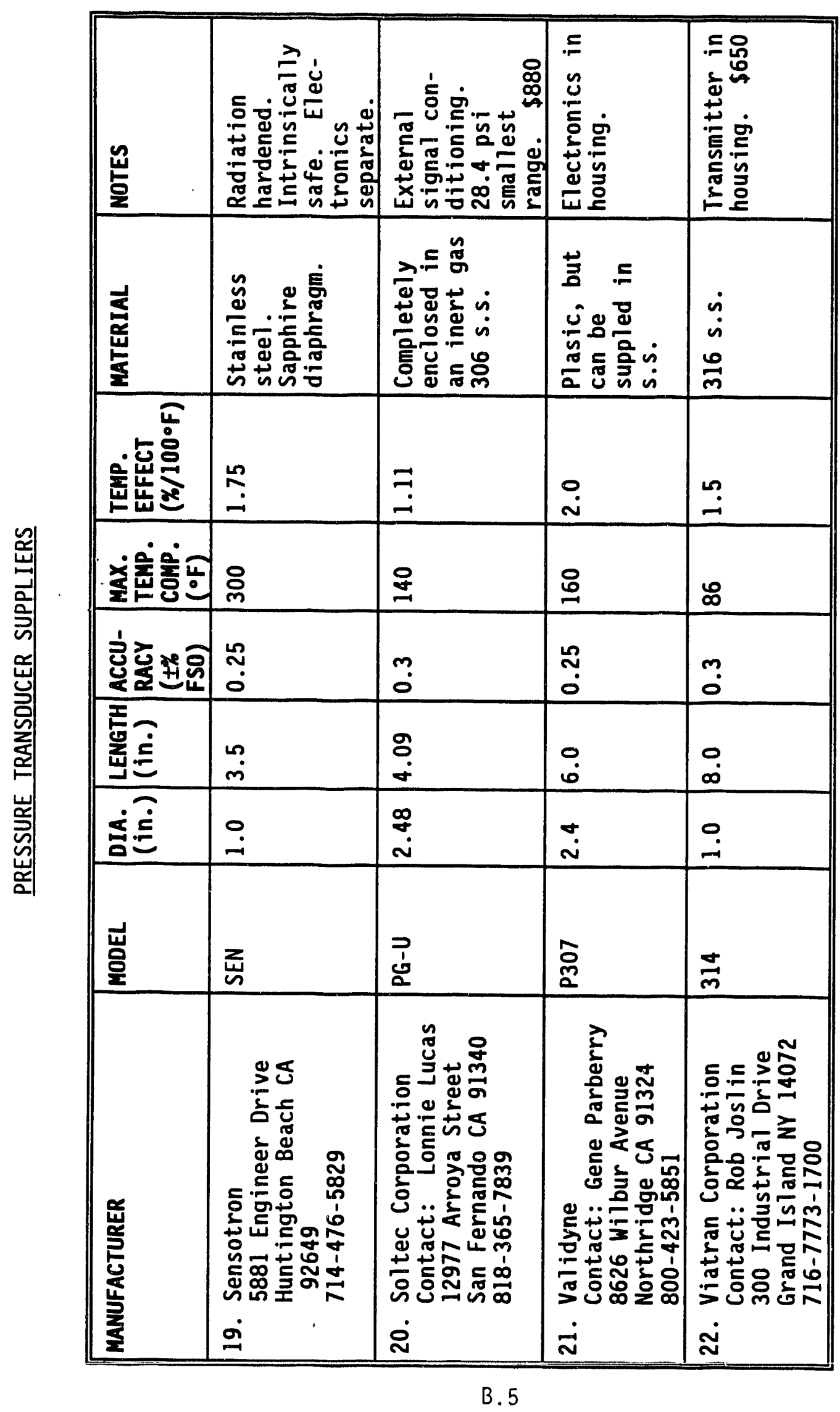




\section{DISTRIBUTION}

No. of

Copies

OFFSITE

2 DOE/Office of Scientific and Technical
Information

ONSITE

DOE Richland Operations Office

R. F. Christensen, A4-02

6 Westinghouse Hanford Company

H. Babad

G. D. Johnson

N. W. Kirch

J. W. Lentsch

C. P. Schroeder

W. F. White

Kaiser Engineers Hanford Company

P. J. McGrath

15 Pacific Northwest Laboratory

R. T. Allemann

J. B. Colson

F. M. Cuta

M. R. Kreiter

W. R. Park

T. J. Peters (3)

D. M. Strachan

Publishing Coordination

Technical Report Files (5)

Distr.1 

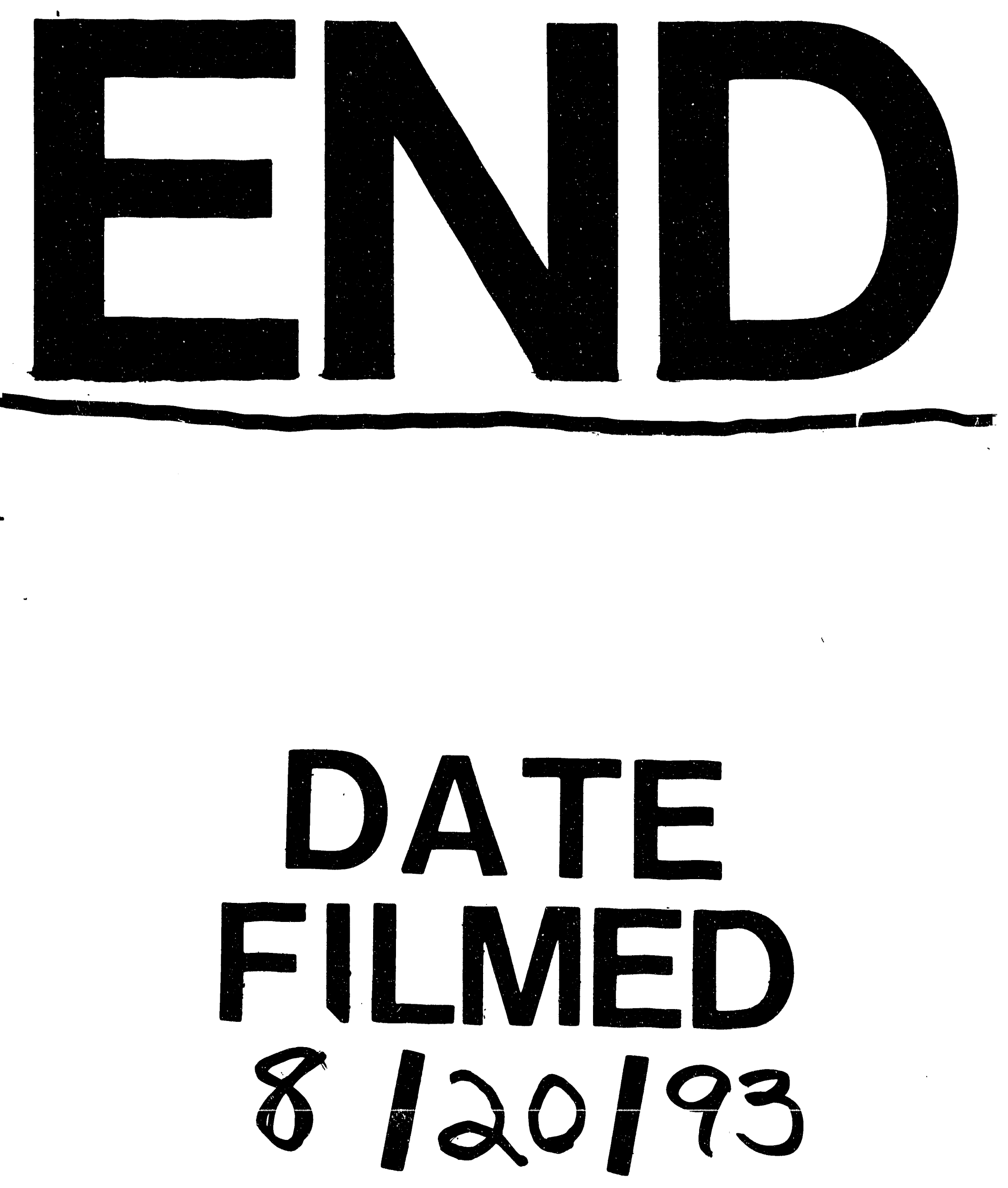
